Portland State University

PDXScholar

7-7-1993

\title{
A New Approach to the Optimal Filtering of Differential Phase Measurements of GPS Signal in the Precision Survey
}

Shengan Wang

Follow this and additional works at: https://pdxscholar.library.pdx.edu/open_access_etds

Part of the Signal Processing Commons

Let us know how access to this document benefits you.

\section{Recommended Citation}

Wang, Shengan, "A New Approach to the Optimal Filtering of Differential Phase Measurements of GPS Signal in the Precision Survey" (1993). Dissertations and Theses. Paper 4633.

https://doi.org/10.15760/etd.6517

This Thesis is brought to you for free and open access. It has been accepted for inclusion in Dissertations and Theses by an authorized administrator of PDXScholar. Please contact us if we can make this document more accessible: pdxscholar@pdx.edu. 
AN ABSTRACT OF THE THESIS OF Shengan Wang for the Master of Science in Electrical and Computer Engineering presented July 7, 1993.

Title: A New Approach to the Optimal Filtering of Differential Phase Measurements of GPS Signal in the Precision Survey

\section{APPROVED BY THE MEMBERS OF THE THESIS COMMITTEE:}

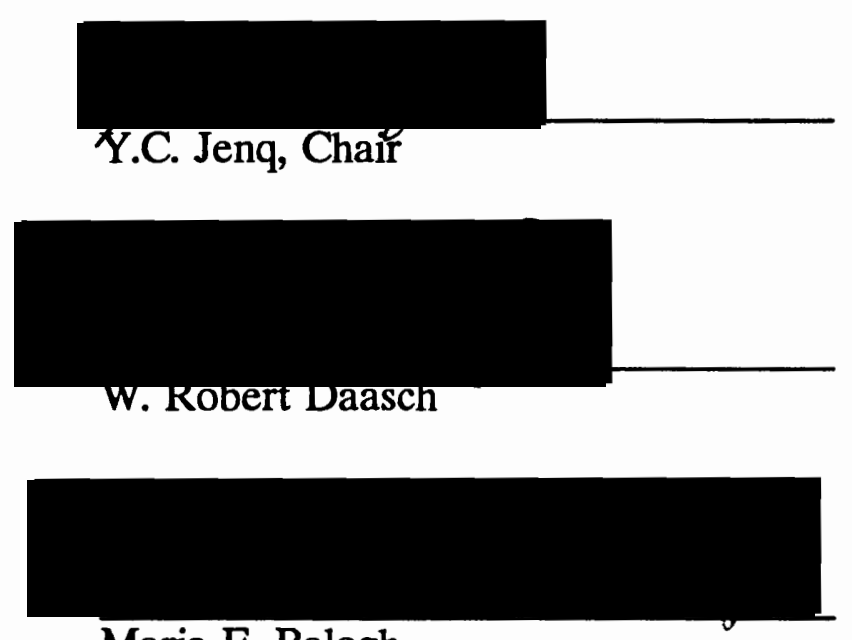

Maria E. Balogh

The Global Positioning System (GPS) has become popular research and application interests in surveying and many other areas. Nowadays, the accuracy of the Differential GPS can easily reach the order of a few meters. Yet, there are still many ways to exploit the GPS system signal carrier to improve the accuracy to 
less than meter level. In this thesis, a new approach to improve the accuracy to less than meter level is presented while the observer is in the dynamic situation. In order to reach the sub-meter accuracy, we measure on the carrier phase difference (The $\mathrm{L} 1$ carrier frequency is $1575.42 \mathrm{Mhz}, \lambda=19 \mathrm{~cm}$ ) between a reference point $\mathrm{A}$ and a primary point $\mathrm{B}$. This actually means we work on the accuracy of centi-meter. In this proposed method of the precision survey, first the Differential GPS is used to fix the position in the accuracy of meter level, and then by measuring the signal carrier relative difference we can work on the accuracy in the accuracy level of the wavelength $(19 \mathrm{~cm})$. The measuring on the relative carrier phase will introduce the problem of initial modulo $2 \pi$ phase (integer wavelength) ambiguity. To solve the initial integer ambiguity, A Multiple Model Estimation Algorithm (MMEA) which was developed by D.T. Magill in 1965 is applied. The MMEA is composed of a bank of parallel Kalman filters, all operating on the input measurement sequence simultaneously. Each filter in the bank of filters is modeled around a different hypothesis. The number of the required parallel filters is the number of hypothesis of integer ambiguity which is determined by the error range of the differential phase measurement. And the error range of the differential phase measurement is related to the accuracy of the Differential GPS.

The precision positioning by MMEA method has some advantage compares with other methods now being used.

. It does not require continuous observation of the satellites initially. 
. Kalman filter is recursive technique. So it has the potential of on-line.

. Kalman filter is widely used in navigation and approved to be very efficient and versatile.

Computer simulation results are given for a hypothetical GPS system. They demonstrate that the MMEA can effectively solve the integer wavelength ambiguity problem in dynamic situation. The simulation results presented are especially encouraging with regard to the flexibility and efficiency in precision survey.

A further improvement of precision surveying by GPS is also discussed in the last Chapter. By using Markov Model and Verterbi Algorithm, a more flexible and reliable precision surveying method could be available. 


\section{A NEW APPROACH TO THE OPTIMAL \\ FILTERING OF DIFFERENTIAL PHASE \\ MEASUREMENTS OF GPS SIGNAL IN THE PRECISION SURVEY}

by

SHENGAN WANG

A thesis submitted in partial fulfillment of the requirements of the degree of

MASTER OF SCIENCE

in

ELECTRICAL AND COMPUTER ENGINEERING

Portland State University

1993 


\section{TO THE OFFICE OF GRADUATE STUDIES:}

The members of the Committee approve the thesis of Shengan Wang presented July 7, 1993.

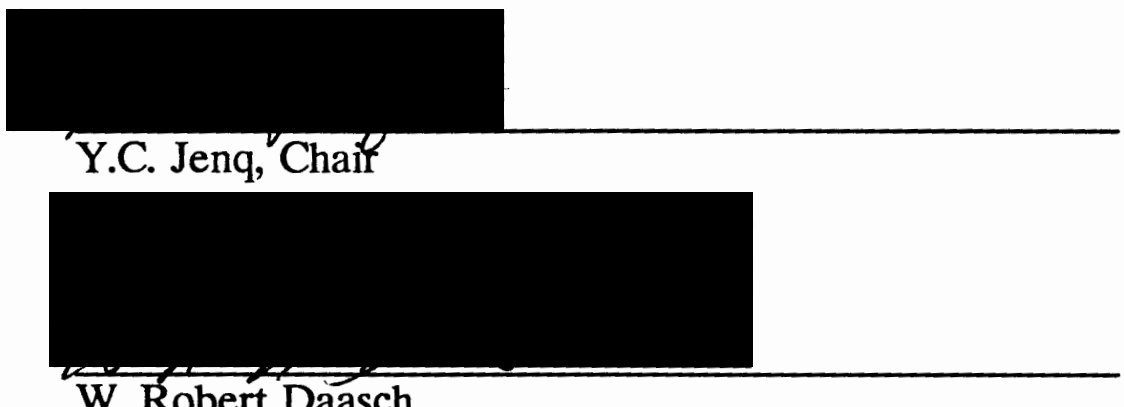

W. Robert Daasch

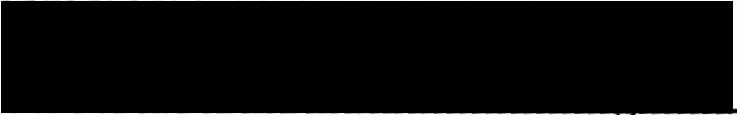

Maria E. Balogh

APPROVED:

Rolf Schaumann, Chair, Department of Electrical Engineering

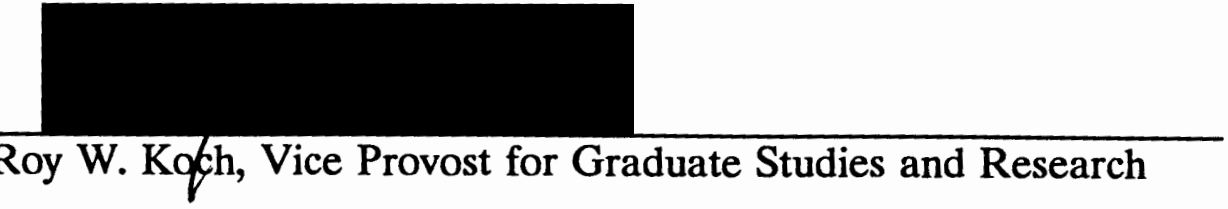




\section{ACKNOWLEDGEMENTS}

A number of people have assisted in my thesis. I would like to take this opportunity to thank them.

I would like to thank Dr. Y.C. Jenq, Chair of the Committee, for his direction in my graduate works and throughout my stay at Portland State University.

I would also very much like to thank the other Committee members: Dr. W. Robert Daasch and Dr. Maria E. Balogh for their assistance and suggestions in preparation of the thesis.

I am also grateful to Shirley Clark for her assistance and support.

Most of all, I am grateful to my wife, Xiaohong, for her support and understanding through all the years of my graduate studies at Portland State University. 
TABLE OF CONTENTS

PAGE

ACKNOWLEDGEMENTS $\ldots \ldots \ldots \ldots \ldots \ldots \ldots \ldots \ldots \ldots \ldots$ iii

LIST OF TABLES $\ldots \ldots \ldots \ldots \ldots \ldots \ldots \ldots \ldots \ldots \ldots \ldots \ldots$, vi

LIST OF FIGURES $\ldots \ldots \ldots \ldots \ldots \ldots \ldots \ldots \ldots \ldots \ldots \ldots \ldots$ vii

\section{CHAPTER}

I INTRODUCTION $\ldots \ldots \ldots \ldots \ldots \ldots \ldots \ldots \ldots \ldots \ldots, 1$

II BASICS OF GLOBAL POSITIONING SYSTEM ....... 4

Overview..................... 4

Solution of GPS Navigation Equations ......... 8

Concept of Geometric Dilution of Precision ...... 12

Accuracy of GPS and Error Sources .......... 16

Performances of GPS

and the Other Navigation Systems ........... 19

III DIFFERENTIAL GPS $\ldots \ldots \ldots \ldots \ldots \ldots \ldots \ldots, 21$

Concept of Differential GPS .............. 21

Accuracy of Differential GPS ............ 22

Performance $\ldots \ldots \ldots \ldots \ldots \ldots \ldots \ldots . \quad 25$ 
IV CURRENT METHODS OF CARRIER PHASE MEASUREMENT IN PRECISION SURVEY . . . . . .

Overview ..................... 27

Static Surveying ............... 28

Continuous Phase Tracking $\ldots \ldots \ldots \ldots \ldots \ldots \quad 30$

V REVIEW OF CONDITIONAL MEAN AND MULTIPLE MODEL ESTIMATION ALGORITHM . . . . .

The Conditional Mean as the Best Estimate ...... 31

Multiple Model Estimation Algorithm . . . . . . . 34

VI APPLICATION OF MMEA

IN PRECISION POSITIONING. . . . . . . . . . . . . 39

Dynamic State Process for GPS Observer . . . . . . 39

Solution of Ambiguity Integer by MMEA . . . . . . 42

VII SIMULATION AND ANALYSIS OF THE RESULTS . . . 46

VIII $\quad$ SUMMARY $\ldots \ldots \ldots \ldots \ldots \ldots \ldots \ldots \ldots \ldots \ldots \ldots \ldots \ldots \ldots \ldots$

Review ...................... 54

Future Work ............... 54

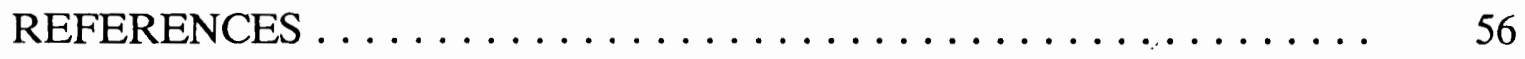
APPENDICES

A THE GENERATION OF $Z_{\mathrm{K}}$ MEASUREMENT. . . . . . 57

B THE AMBIGUITY INTEGER HYPOTHESIS TESTS . . . 59

C KALMAN FILTERING OF $Z_{\mathrm{K}} \ldots \ldots \ldots \ldots \ldots \ldots \ldots$ 


\section{LIST OF TABLES}

TABLE

PAGE

I Dataframe and Subframe Structure $\ldots \ldots \ldots \ldots \ldots \ldots$

II $\quad$ Error Sources in GPS . . . . . . . . . . . . . 17

III Performance Comparison of

Current Navigation Systems . . . . . . . . . . . . 20 


\section{LIST OF FIGURES}

1. The GPS of 24 Satellites Constellation $\ldots \ldots \ldots \ldots \ldots \ldots$

2. Satellite Orbit Tracks on the Ground $\ldots \ldots \ldots \ldots \ldots \ldots 7$

3. The Earth Center Coordinate System ........... 8

4. The Differential GPS Basic Configuration .......... 21

5. Degradation of Accuracy of Differential GPS ........ 23

6. Static Surveying $\ldots \ldots \ldots \ldots \ldots \ldots \ldots \ldots \ldots \ldots \ldots$

7. Bank of Kalman Filters in Parallel ............. 36

8. Random Walk Model of GPS Observer ........... 40

9. Integrated Random Walk Model of GPS Observer . . . . . . 40

10. Position-Velocity-Acceleration Model of High Dynamic GPS Observer ............... 41

11. Error Phase Difference $X_{k} \ldots \ldots \ldots \ldots \ldots \ldots \ldots \ldots$

12. Parallel Filter Bank of the MMEA ............. 44

13. Actual Phase Difference $\ldots \ldots \ldots \ldots \ldots \ldots \ldots \ldots \ldots$

14. Measurable Phase Difference .............. 47

15. Ambiguity Integer Hypothesis Test I . . . . . . . 48

16. Ambiguity Integer Hypothesis Test II ........... 48

17 Ambiguity Integer Hypothesis Test III . . . . . . . . . 49 
18 Ambiguity Integer Hypothesis Test IV . . . . . . . . . . 49

19. Kalman Filter Output $I \ldots \ldots \ldots \ldots \ldots \ldots \ldots \ldots \ldots$

20. Kalman Filter Output II ................ 50 


\section{CHAPTER I}

\section{INTRODUCTION}

The Global Positioning System (GPS) is a global satellite navigation system which has been in process of implementing and operating by the Department of Defense of the United States of America. The GPS system provides position services of two levels of accuracy, the Precise Position Service (PPS) and the Standard Position Service (SPS). The Precise Position Service is for the military and the authorized users only and the Standard Position Service is open to the civilian community. Applications of GPS in surveying and many other areas has become popular research interests. In the civilian community, the Differential GPS is widely used to improved the position accuracy of SPS. Nowadays, the accuracy of the Differential GPS is a few meters[1]. Yet, there are still many ways to exploit the GPS system's signal carrier to improve the accuracy to be within one meter. A new approach is presented in this thesis to improve the accuracy to be within one meter while the observer is in the dynamic situation. In order to reach the desired accuracy, we first use the Differential GPS to fix the position in the accuracy of meter level. We then measure the carrier relative phase difference (The L1 carrier frequency is $1575.42 \mathrm{Mhz}, \lambda=19 \mathrm{~cm}$ ) between a reference point $\mathrm{A}$ and a primary point $\mathrm{B}$. We then fine tune the accuracy by adding up the 
correction term calculated from the carrier relative phase difference. We actually work on the accuracy in the level of the wavelength $(19 \mathrm{~cm})$. The measuring of the carrier relative phase difference will introduce the problem of initial modulo $2 \pi$ phase (integer wavelength) ambiguity. To solve the ambiguity, a Multiple Model Estimation Algorithm (MMEA) which was developed by D.T. Magill is applied[2]. The MMEA is composed of a bank of parallel Kalman filters[3], all operating on the input measurement sequence simultaneously. Each filter in the bank is modeled around a different hypothesis. The number of required parallel filters is the number of hypothesis of ambiguity integer which is determined by the error range of the differential phase measurement. The error range of the differential phase measurement is related to the accuracy of the Differential GPS.

The precision positioning by MMEA method has some advantages over the other methods now being used.

. It does not require continuous observation of the satellites initially.

. Kalman filtering is a recursive technique, and it can be used on-line.

. Kalman filtering is widely used in navigation and has proved to be very efficient and versatile.

Computer simulation results are given for a hypothetical GPS system. They demonstrate that the MMEA can effectively solve the integer wavelength ambiguity problem in a dynamic situation. The simulation results presented are especially encouraging with regard to the flexibility, efficiency, and accuracy.

The basic organization of the paper is as follows. Chapters II and III are 
devoted to basic concepts of GPS, its implementation, and Differential GPS, which drastically improves the accuracy of GPS positioning. Chapter IV discusses the current available methods which further improve the accuracy of Differential GPS positioning. Chapter $\mathrm{V}$ is theoretical preparation for a new proposal in our paper. Chapter VI applies the MMEA to solve the ambiguity problem in measuring the carrier relative phase difference. Chapter VII is the computer simulation. Chapter VIII reviews the results and lays the groundwork for the future research. 
CHAPTER II

\section{BASICS OF GLOBAL POSITIONING SYSTEM}

\section{OVERVIEW}

The Global Positioning System (GPS) is so far the world's largest navigation system. The GPS system consists of three basic elements: the navigation satellites, the ground control and monitoring system, and the user equipment. The GPS system is still in its process of being completed. When the project is completed, the system will consist of a constellation of 24 satellites operating in 12-hour orbits at an altitude of $20,183 \mathrm{~km}$. It will provide visibility of 6 to 11 satellites at 5 degrees or more above the horizon to users located anywhere in the world at any time. The satellites transmit at the two carrier frequencies called L1 (1575.42 Mhz) and L2 (1227.6 Mhz)[4]. L1 are modulated by both the P code which provides for Precise Position Service (PPS) and C/A code (Clear/Acquisition) which provides for Standard Position Service (SPS). L2 has P code only. Both the P code and the C/A code are Pseudo Random Noise (PRN) codes. $\mathrm{P}$ code has a chip rate of $10.23 \mathrm{Mhz}$ and $\mathrm{C} / \mathrm{A}$ code has a chip rate of 1.023 Mhz. The PRN code modulates the navigation message which is 50 bands per second. Each satellite uses its own unique set of PRN code so the GPS user 
TABLE I

DATAFRAME AND SUBFRAME STRUCTURE

\begin{tabular}{|c|c|c|c|c|}
\hline Sub- & \multicolumn{3}{|c|}{ Dataformat of Navigation Message } & \\
\hline 1 & TLM & HOW & $\begin{array}{l}\text { DATABLOCK I } \\
\text { Clock correction }\end{array}$ & $\begin{array}{l}\text { One } \\
\text { frame }\end{array}$ \\
\hline 2 & TLM & HOW & $\begin{array}{l}\text { DATABLCOK II } \\
\text { Ephemeris }\end{array}$ & in $30 \mathrm{sec}$. \\
\hline 3 & TLM & HOW & $\begin{array}{l}\text { DATABLOCK III } \\
\text { Ephemeris continued }\end{array}$ & \\
\hline 4 & TLM & HOW & $\begin{array}{l}\text { DATABLOCK IV } \\
\text { Message }\end{array}$ & \\
\hline 5 & TLM & HOW & $\begin{array}{l}\text { DATABLCOK V } \\
\text { ALMANAC } \\
\text { (25 frames) }\end{array}$ & \\
\hline
\end{tabular}

equipment can receive several satellite signals simultaneously at the same frequency by code division. 
The navigation message consists of a dataframe of 1,500 bits. This frame is composed of five subframes of 300 bits. With a data rate of $50 \mathrm{bps}$ the whole dataframe has duration of 30 seconds. The contents of navigation message are as shown in the Table I[4]. The TLM is telemetry data for ground control segment. The HOW is used for $\mathrm{P}$ code synchronization. The message in DATABLOCK IV is not used right now. The rest of the navigation message, clock correction, ephemeris and almanac are used for navigation calculation. The Navigation position fixes can be made in a time interval from tens of seconds to several minutes, depending on the sophistication of the receiving system and the initial GPS system information the user equipment has in its memory.

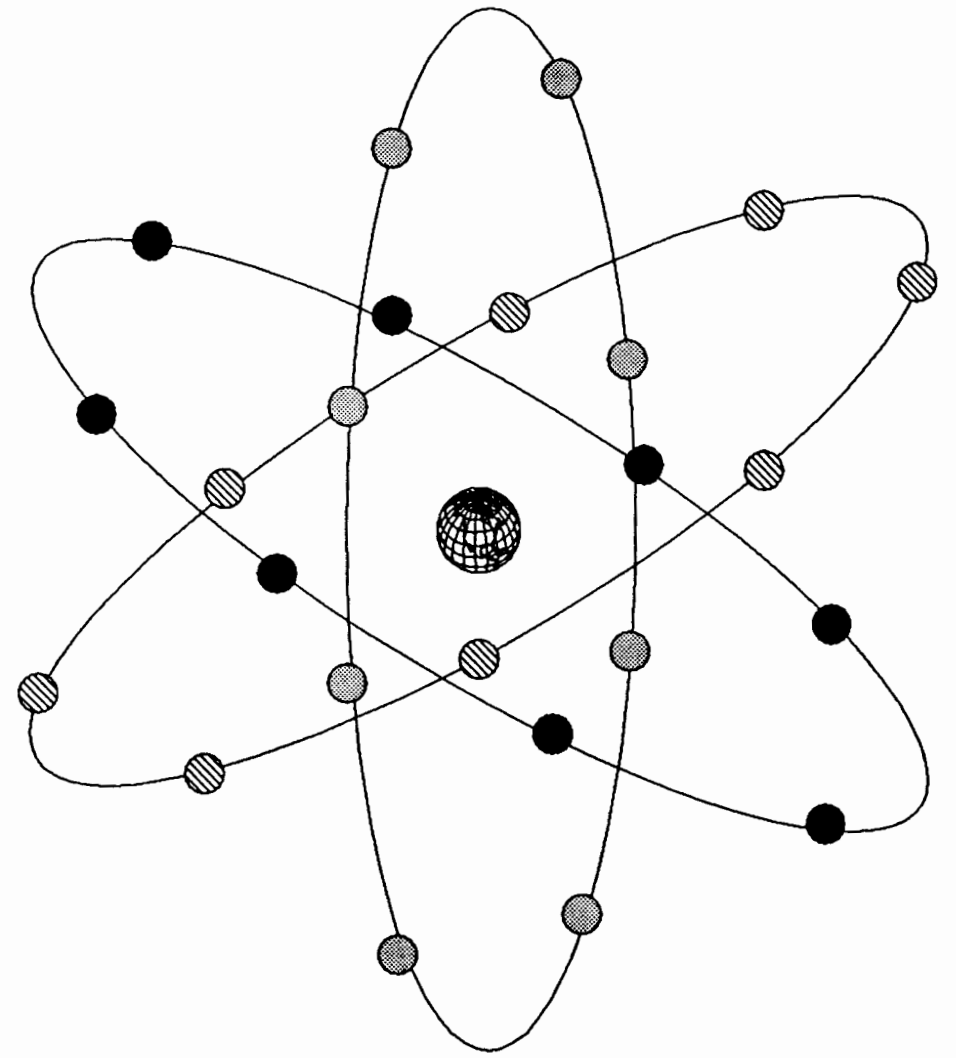

Figure 1. The GPS of 24 Satellites Constellation. 
Figure 1 shows the GPS satellite configuration of 24 satellites. There are three orbit planes, each inclined by $63^{\circ}$ with respect to the equatorial plane and offset from one another by $120^{\circ}$ in longitude. There are eight satellites in each circular 12 hours orbits plane. The Figure 2 shows the orbit tracks of the satellite on the ground.

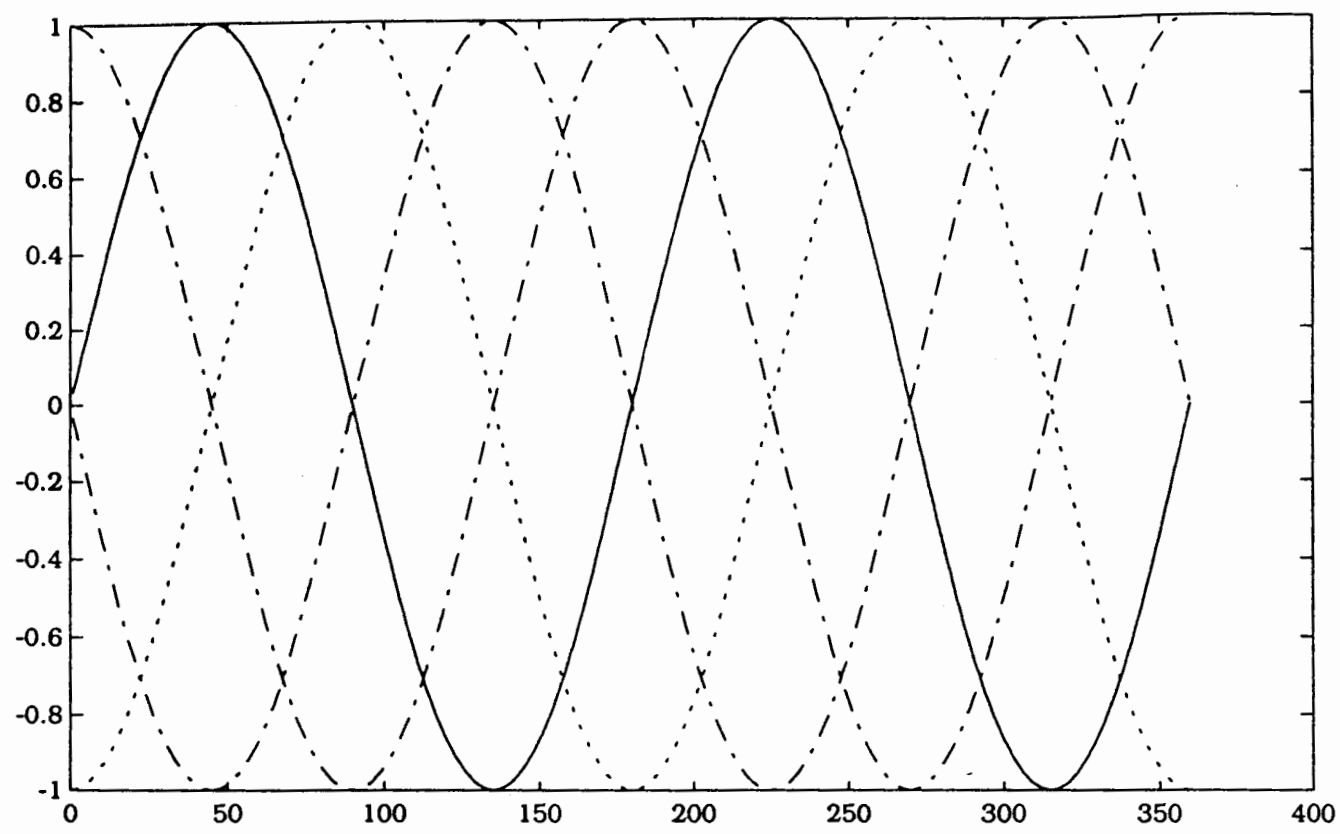

Figure 2. Satellite Orbit Tracks on the Ground.

Each satellite crosses the equator in a northerly direction twice a day at two points separated by exactly $180^{\circ}$ with a fixed sinusoidal ground track. Satellites with different phases but in the same orbit plane have different ground tracks which are displaced by the amount of earth rotation between crossings. Thus if a satellite crosses (northerly) the equator at $0^{\circ}$ or $180^{\circ}$ longitude, another satellite in the same plane, but six hrs behind, crosses (northerly) the equator at $90^{\circ} \mathrm{E}$ and 
$90^{\circ} \mathrm{W}$ longitude and crosses southerly at $0^{\circ}$ and $180^{\circ}$ longitude.

\section{SOLUTION OF GPS NAVIGATION EQUATIONS}

Figure 3 illustrates an earth-centered inertial coordinate system. At zero time, the $\mathrm{X}$ axis passed through the intersection of the equator and prime meridian, the $\mathrm{Z}$ axis pass through the North Pole, and $\mathrm{Y}$ axis completes the righthanded coordinate system. Because of the earth's rotation, the $\mathrm{X}$ and $\mathrm{Y}$ coordinates change in longitude about 15 deg per hour.

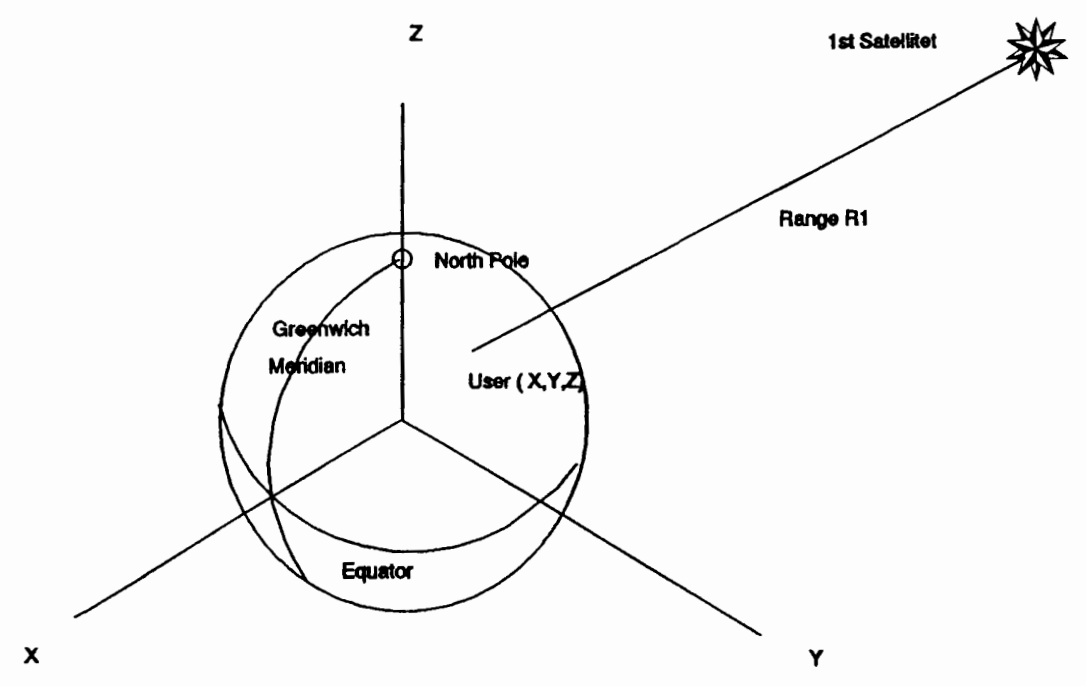

Figure 3. The Earth Center Coordinate System.

Shown in Figure 3 are the user position (X, Y, and Z) and the position of 
Satellite No.1 (X1, Y1, and Z1). The range distance between the user and Satellite No. 1 is shown as R1. And the range distance to the Satellite No. 2, No. 3, and No. 4 are R2, R3, and R4.

The basic equations using four satellites are

$$
\begin{aligned}
& \operatorname{Sqrt}\left[\left(X-X_{1}\right)^{2}+\left(Y-Y_{1}\right)^{2}+\left(Z-Z_{1}\right)^{2}\right]+T=R_{1} \\
& \operatorname{Sqrt}\left[\left(X-X_{2}\right)^{2}+\left(Y-Y_{2}\right)^{2}+\left(Z-Z_{2}\right)^{2}\right]+T=R_{2} \\
& \operatorname{Sqrt}\left[\left(X-X_{3}\right)^{2}+\left(Y-Y_{3}\right)^{2}+\left(Z-Z_{3}\right)^{2}\right]+T=R_{3} \\
& \operatorname{Sqrt}\left[\left(X-X_{4}\right)^{2}+\left(Y-Y_{4}\right)^{2}+\left(Z-Z_{4}\right)^{2}\right]+T=R_{4}
\end{aligned}
$$

where $\mathrm{X}, \mathrm{Y}, \mathrm{X}$, and $\mathrm{T}$ are user position and clock bias (unknowns); $\mathrm{X}_{\mathrm{i}}, \mathrm{Y}_{\mathrm{i}}$ and $\mathrm{Z}_{\mathrm{i}}$ are the ith satellite position; $\mathrm{i}=1,2,3,4$ (known); and $\mathrm{Ri}$ is the pseudo-range measurements to the ith satellite. Here the quantities $R_{1}, R_{2}, R_{3}$ and $R_{4}$ are "pseudo" ranges because they are the sum of the actual range displacements plus the offset due to user time error. For convenience, the unit of time is scaled to the unit of length by the velocity of light. The satellite positions are known, and the four unknowns are user position and the user clock error. It should be emphasized that while precision atomic frequency standards are used in the satellites and the monitor stations, there is no requirement for GPS users to have a precision clock. Ordinary quartz crystal frequency standards are adequate for the user since the user is continuously computing time from the four pseudo-range measurements.

The Eq. (2.1) is nonlinear. While it is possible to solve these equations directly as they are shown, but all user equipments employ a much simpler linearized version of these equations. The basic navigation equations can be 
linearized by employing incremental relationships as follows.

Let

$\mathrm{Xn}, \mathrm{Yn}, \mathrm{Zn}, \mathrm{Tn}$ be nominal (a priori best estimate) values of $\mathrm{X}, \mathrm{Y}$, $\mathrm{Z}, \mathrm{T}$.

$\Delta \mathrm{X}, \Delta \mathrm{Y}, \Delta \mathrm{Z}, \Delta \mathrm{T}$ be the corrections to these nominal values.

$R_{n i}$ be the nominal pseudo-range measurement from the ith satellite.

$\Delta R_{i}$ be the difference between the actual and nominal measurements.

Therefore,

$$
\begin{aligned}
& X=X_{n}+\Delta X \\
& Y=Y_{n}+\Delta Y \\
& Z=Z_{n}+\Delta Z \\
& T=T_{n}+\Delta T \\
& R_{i}=R_{n i}+\Delta R_{i} \\
& R_{n i}=\operatorname{Sqrt}\left[\left(X_{n}-X_{i}\right)^{2}+\left(Y_{n}-Y_{i}\right)^{2}+\left(Z_{n}-Z_{i}\right)^{2}\right]+T_{n} .
\end{aligned}
$$

Substituting the incremental expressions into the basic equations yields

$$
\begin{aligned}
& \operatorname{Sqrt}\left[\left(X_{n}+\Delta X-X_{i}\right)^{2}+\left(Y_{n}+\Delta Y+Y_{i}\right)^{2}+\left(Z_{n}+\Delta Z+Z_{i}\right)^{2}\right] \\
& =R_{n i}+\Delta R_{i}-T_{n}-\Delta T, \quad i=1,2,3,4 .
\end{aligned}
$$

By ignoring second-order error terms, these equations can be written as

$$
\begin{aligned}
& \operatorname{Sqrt}\left[(X n-X i)^{2}+(Y n-Y i)^{2}+(Z n-Z i)^{2}\right]+ \\
& ((X n-X i) \Delta X+(Y n-Y i) \Delta Y+(Z n-Z i) \Delta Z) / S q r t\left[(X n-X i)^{2}+\right. \\
& \left.(Y n-Y i)^{2}+(Z n-Z i)^{2}\right]
\end{aligned}
$$




$$
=\mathrm{Rni}+\Delta \mathrm{Ri}-\mathrm{Tn}-\Delta \mathrm{T} \text {. }
$$

Substituting Eq. (2.2) into Eq. (2.4), we get

$$
\begin{aligned}
& \left((X n-X i) /\left(R_{n i}-T_{n}\right)\right) \Delta X+\left((Y n-Y i) /\left(R_{n i}-T_{n}\right)\right) \Delta Y \\
& +\left((Z n-Z i) /\left(R_{n i}-T_{n}\right)\right) \Delta Z+\Delta T=\Delta R i .
\end{aligned}
$$

For $\mathrm{i}=1,2,3,4$, the above equation will yield four equations which are linearized equations that relate pseudo-range measurements to the desired user navigation information as well as the user's clock bias.

The known quantities of the right-hand side of the equation are actually incremental pseudo-range measurements. They are the differences between the actual measured pseudo-ranges and the measurements that had been predicted by the user's computer base on the knowledge of satellite position and the user's most current estimate of his position and clock bias. The quantities to be computed, $\Delta \mathrm{X}, \Delta \mathrm{Y}, \Delta \mathrm{Z}$, and $\Delta \mathrm{T}$, are corrections that the user will make to his current estimate of position and clock biases. The coefficients of these quantities on the left-hand side are the direction cosines of the line of sight (LOS) from the user to the satellite as projected along the $\mathrm{X}, \mathrm{Y}$, and $\mathrm{Z}$ coordinates. For all four equations, the coefficient in front of $\Delta T$ is unity. These linearized equations can be conveniently expressed in matrix notation.

Let

$$
\begin{aligned}
& \mathbf{r}=\text { the four-element pseudo-range measurement difference vector } \\
& \mathbf{r} \equiv[\Delta \mathrm{R} 1 \Delta \mathrm{R} 2 \Delta \mathrm{R} 3 \Delta \mathrm{R} 4]^{\mathrm{T}} \\
& \mathbf{x}=\text { the user position and time correction vector }
\end{aligned}
$$




$$
\begin{aligned}
\mathbf{x} \equiv & {[\Delta X \Delta Y \Delta Z \Delta T]^{\mathrm{T}} } \\
\mathbf{A}= & \text { the } 4 \text { X } 4 \text { solution matrix } \\
\mathbf{A} \equiv & {[\mathrm{a} 11, \mathrm{a} 12, \mathrm{a} 13,1 ;} \\
& \mathbf{a} 21, \mathrm{a} 22, \mathrm{a} 23,1 ; \\
& \mathbf{a} 31, \mathrm{a} 32, \mathrm{a} 33,1 ; \\
& \mathrm{a} 41, \mathrm{a} 42, \mathrm{a} 43,1]
\end{aligned}
$$

where $\mathrm{Aij}$ is the direction cosine of the angle between the range to the ith satellite and the jth coordinate.

Therefore

$$
A x=r \text { or } x=A^{-1} \mathbf{r}
$$

The last equation presented compactly expresses the relationship between pseudo-range measurements and user position and clock bias. So the navigation equations are solved by recursive method in process of estimating, updating and then estimating and updating again, until to the resolution the GPS receiver.

\section{CONCEPT OF GEOMETRIC DILUTION OF PRECISION}

Since the relationship expressed in Eq. (2.6) is linear, it also can be used to express the relationship between the errors in pseudo-range measurement and the user quantities. This relationship is therefore

$$
\epsilon_{\mathbf{x}}=\mathbf{A}^{-1} \epsilon_{\mathrm{r}}
$$

where $\epsilon_{\mathrm{r}}$ represents the pseudo-range measurement errors and $\epsilon_{\mathrm{x}}$ the 
corresponding errors in user position and clock bias.

Let us now consider the covariance matrix of the expected errors in pseudo-range measurement and the covariance matrix of the user quantities. The first covariance measurement is a $4 \times 4$ array composed of the expected values of the squares and products of the errors in the pseudo-range measurements. The diagonal terms in the matrix, namely the squares of the expected errors, are the variances; i.e., the squares of the expected $1 \delta$ values of the pseudo-range measurement errors. The off-diagonal terms are the covariance between the pseudo-range measurement and reflect the correlations to be expected in these measurements. Likewise, the covariance matrix for the user quantities is composed of the expected values of the squares and products of the errors in the user quantities. The diagonal terms are the variance or the squares of the $1 \delta$ errors in user position and time, while the off-diagonal terms reflect the correlations in these errors. These covariance matrices are given by

$$
\begin{aligned}
& \operatorname{Cov}(\mathbf{r})=\mathrm{E}\left(\boldsymbol{\epsilon}_{\mathbf{r}} \boldsymbol{\epsilon}_{\mathbf{r}}{ }^{\mathbf{T}}\right) \\
& \operatorname{Cov}(\mathbf{x})=\mathrm{E}\left(\epsilon_{\mathbf{x}} \boldsymbol{\epsilon}_{\mathbf{x}}{ }^{\mathbf{T}}\right)
\end{aligned}
$$

where the symbol E( ) designates "expected value" of the quantity inside the braces.

Upon substitution, the matrix relationship between the two covariance matrices becomes

$$
\operatorname{COV}(\mathbf{x})=\mathbf{A}^{-1} \operatorname{COV}(\mathbf{r}) \mathbf{A}^{-\mathrm{T}}
$$


An alternate formulation for this relationship, based on a straightforward matrix algebra manipulation, is

$$
\operatorname{COV}(\mathbf{x})=\left[\mathrm{A}^{\mathrm{T}} \operatorname{COV}(\mathbf{r})^{-1} \mathrm{~A}\right]^{-1}
$$

Note that the relationship between the pseudo-range measurement errors and the user's position and clock bias errors are only a function of the solution matrix $\mathbf{A}$, which in turn is only a function of the direction cosines of the LOSs from the user to the satellites. In other words, the error relationships are only functions of satellite geometry. An important consideration in the proper use of GPS is the four satellites being used must possess "good" geometric properties. A "good" geometric property is one in which a given level of error in the pseudo-range measurements results in small user errors because of the satellite geometry. This leads to the concept of geometric dilution of precision (GDOP), a measure of how satellite geometry degrades accuracy.

The following assumption regarding pseudo-range measurement errors provides a method of quantitatively determining whether a particular four-satellite geometry is good or bad. Let each individual pseudo-range measurement have an error $(1 \delta)$ of unity, where the expected mean is zero and correlation of errors between satellites is also zero. With these assumptions, the covariance matrix for the errors in the pseudo-range measurements becomes a $4 \times 4$ unity matrix. Thus, for this case, the covariance matrix for user position and clock bias errors is given by

$$
\operatorname{COV}(\mathbf{x})=\left(\mathbf{A}^{\mathbf{T}} \mathbf{A}\right)^{-1}
$$


GDOP is defined as the square root of the trace of $\operatorname{COV}(x)$ when $\operatorname{COV}(\mathbf{r})$ is an identity matrix.

Therefore,

$$
\text { GDOP }=\operatorname{Sqrt}\left[\operatorname{TRACE}\left(\mathbf{A}^{\mathrm{T}} \mathbf{A}\right)^{-1}\right]
$$

Some properties of this quantity can be summarized as follows:

a. GDOP is, in effect, the amplification factor of pseudo-range measurement errors into user errors due to the effect of satellite geometry.

b. GDOP is independent of the coordinate system employed.

c. GDOP is a criterion for designing satellite constellations.

d. GDOP is a means for user selection of the four best satellites from those that are visible.

By letting $V_{x}, V_{y}, V_{z}, V_{T}$ be the variances of user position and time, we have

$$
\text { GDOP }=\operatorname{Sqrt}\left[V_{x}+V_{y}+V_{z}+V_{T}\right] \text {. }
$$

As an alternative to GDOP as a criterion for selecting satellites or evaluating satellite constellations, only some of the variances of user position and time might be used. These are defined as follows:

PDOP, the square root of the sum of the squares of the three components of position error.

HDOP, the square root of the sum of the squares of the horizontal components of position error.

VDOP, the altitude error. 
TDOP, the error in the user clock bias multiplied by the velocity of light. and

$$
\begin{aligned}
& \mathrm{PDOP}^{2}=\mathrm{HDOP}^{2}+\mathrm{VDOP}^{2} \\
& \mathrm{GDOP}^{2}=\mathrm{PDOP}^{2}+\mathrm{TDOP}^{2} .
\end{aligned}
$$

The alternative criterion most frequently used is the position dilution of precision (PDOP). PDOP is also invariant to the coordinate system and is used because the most important consideration in any navigation system is position accuracy, while knowing time is generally a secondary by-product. Another alternative is the horizontal dilution of precision (HDOP), which is most meaningful for users who are using the system primarily to obtain horizontal position.

\section{ACCURACY OF GPS AND ERROR SOURCES}

The accuracy of a navigation system is often characterized by RMS, Root Mean Square, or also called sigma. An accuracy specification of 20 meters at 1 sigma means that $67 \%$ of the positions are likely to have less than 20 meters error. The remaining $33 \%$ may have larger errors.

The GPS position accuracy is degraded by various error sources. Some of these, for instance poor satellite geometry, are predictable. Others, like turbulent propagation errors, are of a true random nature. Table II[5] summarizes a number of error sources and provides their estimated value. The error in the table 
TABLE II

ERROR SOURCES IN GPS

\begin{tabular}{||l|l|c||}
\hline Segment & \multicolumn{1}{|c|}{ Error Source } & Error in meters at $2 \sigma$ \\
\hline $\begin{array}{l}\text { Space } \\
\text { Section }\end{array}$ & $\begin{array}{l}\text { Navigation Signal } \\
\text { - Frequency standard } \\
\text { stability } \\
\text { - L-band delay variation } \\
\text { Space vehicle acceleration } \\
\text { uncertainty } \\
\text { Others }\end{array}$ & 6.0 \\
\hline Control & $\begin{array}{l}\text { Ephemeris prediction and } \\
\text { model implantation } \\
\text { Others }\end{array}$ & 3.0 \\
\hline User Section & $\begin{array}{l}\text { Ionospheric delay } \\
\text { compensation } \\
\text { Tropospheric delay } \\
\text { compensation } \\
\text { Receiver noise and } \\
\text { resolution } \\
\text { Multipath } \\
\text { Others }\end{array}$ & 1.0 \\
\hline
\end{tabular}

is pseudo ranging errors. The RMS of position accuracy in three dimensions, and 
horizontal position accuracy in two dimensions can be obtained by multiplying the PDOP, and HDOP as in Eq. (2.13) and Eq. (2.14) with the pseudo ranging RMS respectively. The RMS of clock accuracy can be obtained by multiplying TDOP with the pseudo ranging RMS.

In the GPS system, all satellites are equipped with atomic clocks. Even though they are very stable, they may still deviate from GPS time by up to one millisecond (300 meters). Since the atomic clocks are the frequency standards for the satellite, controlling all of its operation, unpredicted deviation from GPS time causes positioning errors. The ground control station monitor the time error and update the clock correction term in Datablock I of the navigation message. Based on the satellite surveillance the control station also predicts their future orbital positions in regard to time. The satellite positions in astronomical coordinates are called the ephemerides. The ephemerides errors are caused by difficulties in predicting the correct satellite positions. The ephemerides are influenced by the Earth's gravitational field, the solar wind, the satellite clocks, and the master control station clock. When the satellite signal penetrate the ionosphere they are reflected and therefore delayed. The delay has a well known frequency dependence. The authorized users utilizing both the $\mathrm{L} 1$ and the $\mathrm{L} 2$ frequency can take advantage of the frequency dependence and eliminate the delay. The single frequency users can compensate for the ionospheric delay by using the predicted values included in the satellite message. The signals from low elevation satellite are deviated and delayed in the troposphere. This delay is independent of 
frequency. The error is relatively small. Multipath errors are caused by receiving both direct and reflected signals from a satellite. The other error sources are the errors not modeled.

\section{PERFORMANCE OF GPS AND THE OTHER NAVIGATION SYSTEMS}

There are several key performance objectives for the GPS system which distinguish it from previous satellite and landbased navigation systems. Some of the more important are summarized below for the stand along GPS receiver using C/A code.

. High positioning accuracy.

. Fast initial navigation fix.

. Real-Time navigation for dynamic users

. World-Wide Operation.

. Tolerant to Nonintentional or Intentional Interference.

. Unlimited number of users.

. Cheap and compact size user equipments.

The following table III[5] compares the performance of GPS with the other current navigation systems. 
TABLE III

PERFORMANCE COMPARISON OF CURRENT NAVIGATION SYSTEMS

\begin{tabular}{|l|l|l|l|l||}
\hline & Loran-C & Omega & Radar & GPS \\
\hline Coverage & $\begin{array}{l}1,200 \mathrm{~nm} \text { to } \\
\text { ground } \\
\text { Absolute } \\
\text { 2D }\end{array}$ & $\begin{array}{l}\text { Global to } \\
\text { ground } \\
\text { Absolute } \\
\text { 2D }\end{array}$ & Unlimited & $\begin{array}{l}\text { Global to } \\
\text { ground }\end{array}$ \\
\hline $\begin{array}{l}\text { Signal } \\
\text { reliability }\end{array}$ & $\begin{array}{l}\text { Fair at } 100 \\
\text { Khz }\end{array}$ & $\begin{array}{l}\text { Fair at 10- } \\
14 \mathrm{Khz} \\
\text { Absolute } \\
\text { 3D }\end{array}$ & $\begin{array}{l}\text { Moderate at } \\
5-16 \mathrm{Ghz}\end{array}$ & $\begin{array}{l}\text { High at } \\
1,227 \mathrm{Mhz} \\
\text { and } \\
1,575 \mathrm{Mhz}\end{array}$ \\
\hline Accuracy & $1,500 \mathrm{ft}$ & $1-2 \mathrm{~nm}$ Rms & Variable & $\begin{array}{l}\text { 25 ft for } \\
\text { PPS and } \\
100 \mathrm{ft} \text { for } \\
\text { SPS }\end{array}$ \\
\hline $\begin{array}{l}\text { Application } \\
\text { Versatility }\end{array}$ & $\begin{array}{l}\text { Air, surface } \\
\text { medium } \\
\text { distance }\end{array}$ & $\begin{array}{l}\text { Air, surface, } \\
\text { under-water } \\
\text { long } \\
\text { distance }\end{array}$ & $\begin{array}{l}\text { Weapon } \\
\text { system }\end{array}$ & $\begin{array}{l}\text { All kinds of } \\
\text { applications }\end{array}$ \\
\hline $\begin{array}{l}\text { User } \\
\text { equipment } \\
\text { cost }\end{array}$ & $\begin{array}{l}\text { Moderate to } \\
\text { high }\end{array}$ & $\begin{array}{l}\text { Moderate to } \\
\text { high }\end{array}$ & Very high & $\begin{array}{l}\text { Low to } \\
\text { moderate }\end{array}$ \\
\hline
\end{tabular}


CHAPTER III

\author{
DIFFERENTIAL GPS
}

\title{
CONCEPTS OF DIFFERENTIAL GPS
}

The basic Differential GPS, as illustrated in Figure 4, consists of a reference GPS receiver at a surveyed location, a primary ranging GPS receiver and a communication link between the reference and the primary receivers. The Differential GPS concept could be implemented as follow.

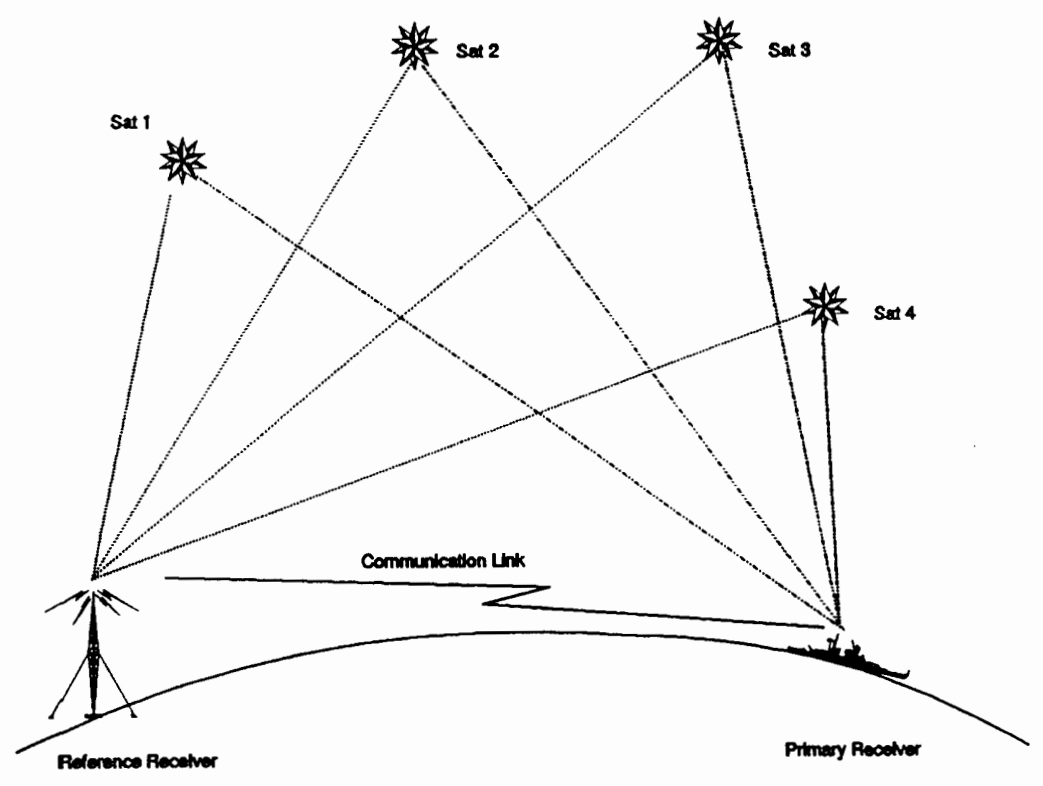

Figure 4. The Differential GPS Basic Configuration. 
The reference receiver is placed in a surveyed location and the position information derived from GPS are compared with surveyed position. The error correction information $(\Delta \mathrm{X}, \Delta \mathrm{Y}, \Delta \mathrm{Z})$ is then transmitted to the primary receiver. The primary receiver use the error correction information from the reference receiver to improve its own positioning accuracy. We assume that the reference receiver and the primary receiver are capable to select the same set of satellites at the same time. So by the differential GPS, the positioning accuracy is drastically improved from $30 \sim 100$ meters to $5 \sim 10$ meters[1]. In next section we will study the error source introduced by the distance between the reference receiver and the primary receiver. This error term is dominant factor in overall error of Differential GPS. An upper bound error of the ranging error is derived in the next section.

\section{ACCURACY OF DIFFERENTIAL GPS}

Let us consider the situation in Figure 5, where the satellite $S$ at location St, but believed to be at location $\mathrm{Sa}$, transmits a message at time $\mathrm{T}_{0}$ believed to be $\mathrm{T}_{0}+\Delta \mathrm{T}$. These discrepancies can be due to genuine inaccuracies in ephemeris and clock error determinations or can be intentionally introduced as a selective availability (SA) technique.

At the reference receiver, the time at which the signal is received and the time at which it is expected are 


$$
\begin{aligned}
& \operatorname{Trc}=\mathrm{R} 1 / \mathrm{C}+\mathrm{T}_{0} \\
& \mathrm{Tep}=(\mathrm{R} 1+\mathrm{r} 1) / \mathrm{C}+\mathrm{T}_{0}+\Delta \mathrm{T} .
\end{aligned}
$$

The total time discrepancy is

$$
\mathrm{r} 1 / \mathrm{C}+\Delta \mathrm{T}
$$

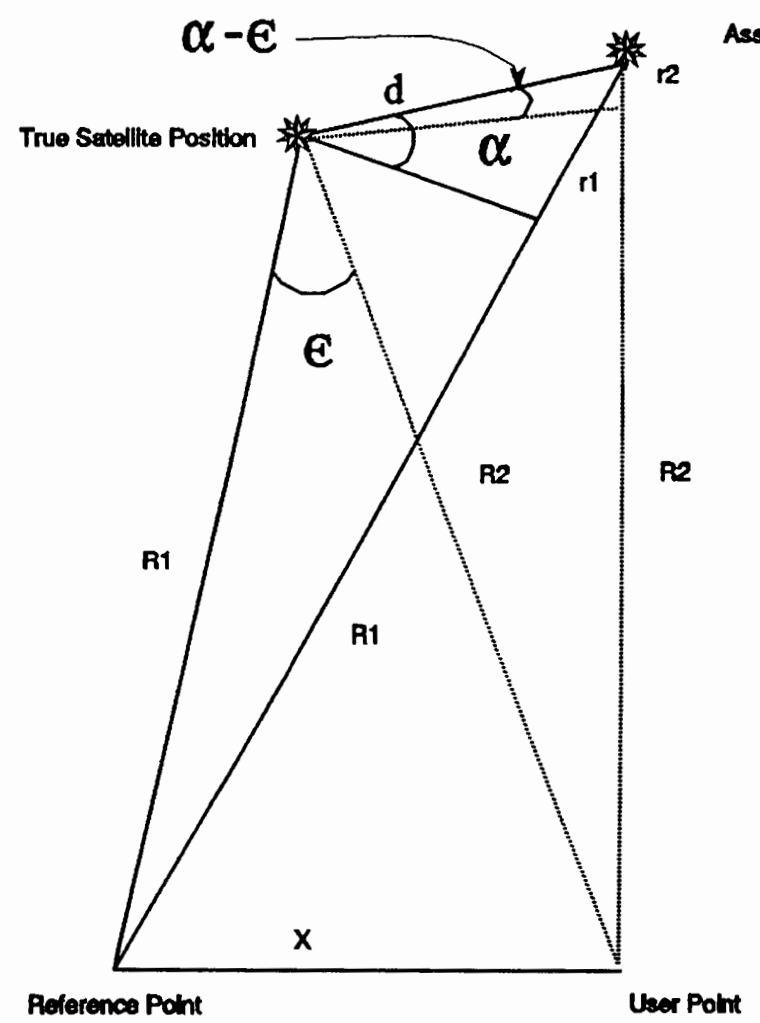

Figure 5. Degradation of Accuracy of Differential GPS.

Let us now consider a primary user, at a distance $\mathrm{X}$ from the reference point. For this user, the total time discrepancy will be

$$
\mathrm{r} 2 / \mathrm{C}+\Delta \mathrm{T}
$$

Therefore, at the primary user location the range error introduced by using the 
discrepancy obtained for the reference point is:

$$
\mathrm{e}=\mathrm{r} 1-\mathrm{r} 2
$$

or

$$
\begin{aligned}
\mathrm{e} & =\mathrm{d} \sin \alpha-\mathrm{d} \sin (\alpha-\epsilon) \\
& =\mathrm{d}(\sin \alpha-\sin \alpha \cos \epsilon+\sin \epsilon \cos \alpha)
\end{aligned}
$$

approximating to first order for small $\epsilon$, we obtain

$$
\mathrm{e}=\epsilon \mathrm{d} \cos \alpha .
$$

The value of $\epsilon$ can be bounded as

$$
\epsilon \leq \mathrm{X} / \mathrm{R} 1,
$$

which will lead to

$$
\mathrm{e} \leq(\mathrm{Xd} \cos \alpha) / \mathrm{R} 1
$$

The worst case will be for $\alpha=0$, and we will get

$$
|\mathrm{e}| \leq \mathrm{Xd} / \mathrm{R} 1 \text {. }
$$

For $X=100 \mathrm{~km}$ and $\mathrm{d}=1 \mathrm{~km}$ and since $\mathrm{R} 1$ is approximately $20,000 \mathrm{~km}$,

$$
|\mathrm{e}| \leq 5 \text { meters. }
$$

The pseudo range correction at the reference point is $\mathrm{r} 1+\mathrm{C \Delta T}$ and is obtained by taking the difference between the time at which the signal is expected and the time at which it is actually received. The time at which it is expected is determined by using the true reference point location and the assumed satellite location. The difference will, therefore, include all propagation delays.

So, the ranging error introduced is linearly proportional to the distance from the reference point. 
In the Earth Centered Earth Fixed coordinates correction terms $(\Delta \mathrm{X}, \Delta \mathrm{Y}$, $\Delta Z$ ) are broadcasted by the ground reference station. An error in position is related to a ranging error by the Position Dilution of Precision (PDOP), i.e.

$$
\mathrm{ex}=\mathrm{PDOPer}
$$

where the ex and er are position and range errors, respectively. And the PDOP is a function of the geometry as discussed in Chapter II.

\section{PERFORMANCE}

As shown in the Eq. (3.12), the Differential GPS cannot make up for the geometrical imperfections due to the satellite constellation, which is characterized by the PDOP. The most significant error sources which the Differential GPS can greatly improve are[5]

1 , SA errors, the deliberately added errors included in the navigation message for security purposes. This type of pseudo range errors will be in the order of approx. 30 meters for 2 sigma.

2 , Ionospheric delays, In isolated areas these errors can reach $20 \sim 30$ meters during the day, and 3-10 meters at the night.

3, Tropospheric delays, the delays can contribute error as much as 4 meter for 2 sigma.

4, Ephemeris errors, the difference between the satellite's true position and its predicted position. This error usually is less than 3 meter. 
5, Satellite clock errors, the difference between the GPS time and the one predicted in the satellite's navigation message. 


\section{CHAPTER IV}

\section{CURRENT METHODS OF CARRIER PHASE MEASUREMENT IN PRECISION SURVEY}

\section{OVERVIEW}

The Differential GPS ensures that the position accuracy will be within a few meters over short baseline (The distance between the primary receiver and the reference receiver). For position accuracy to the level within meter without using the P code, we must measure the carrier phase difference of the GPS signal between the primary and reference points. The carrier with $\mathrm{C} / \mathrm{A}$ code, $\mathrm{L} 1=$ 1575.42 Mhz, has wavelength $\lambda=19 \mathrm{~cm}$. Measurement on carrier phase will lead to the problem of modulo $2 \pi$ phase (or integer wavelength) ambiguity because the initial uncertainty in the relative position between the primary and reference points may be many wavelengths. Currently two techniques are used in solving the integer wavelength ambiguity. 


\section{STATIC SURVEYING}

Here we look into the concepts of static surveying. In the GPS static surveying model as shown in Figure 6, two stationary receivers located at the ends of a baseline are capable to track and measure the phase of the GPS carrier signal arriving at their respective antenna locations.

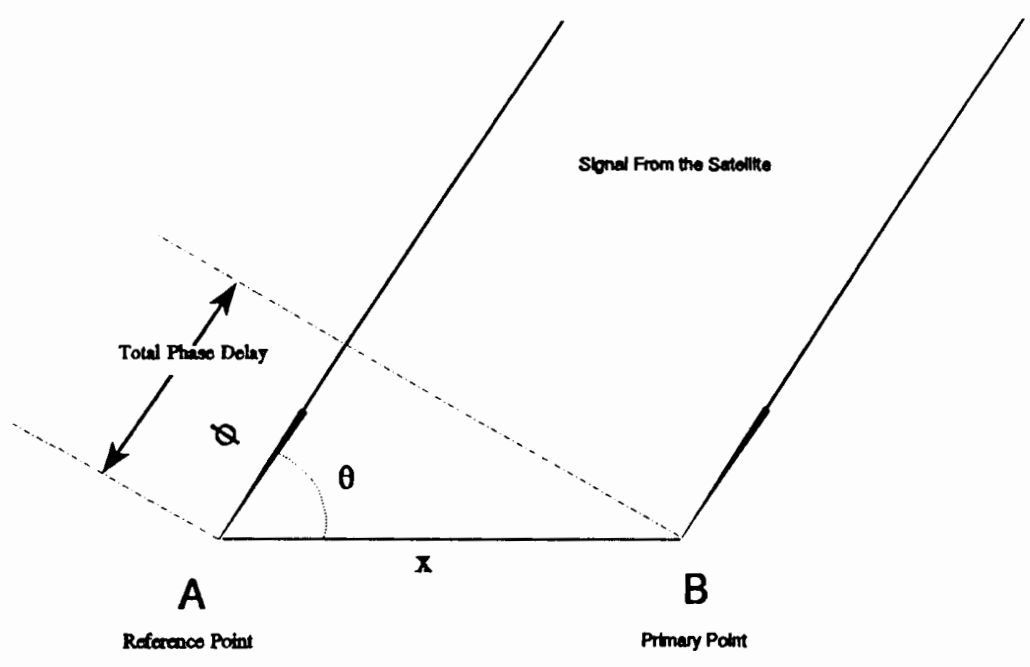

Figure 6. Static Surveying.

It is presumed that all changes in the carrier phase are taken into account from the moment tracking begins when the first measurement is made.

$$
\begin{aligned}
\phi \mathrm{B}-\phi \mathrm{A} & =\mathrm{X} \cos \theta_{0} \\
& =\phi_{0}+\mathrm{N}
\end{aligned}
$$


where $\phi \mathrm{A}, \phi \mathrm{B}$ are the phase at the A point and B point respectively, $\phi_{0}$ is the initial phase difference measurement between B point and A point, $\theta_{0}$ is initial satellite elevation angle, $\mathrm{X}$ is baseline separation between $\mathrm{A}$ point and $\mathrm{B}$ point (in unit of wavelength), and $\mathrm{N}$ is initial integer ambiguity (in unit of wavelength). At the very first instance of achieving carrier track and initial measurement, the true relationship between the phase measurements seen at both receivers location is as Eq.(4.1) with initial ambiguity integer N. For static surveying, the resolution of the initial integer ambiguity can be accomplished by taking a second measurement of phase difference over a period of time. From Eq. (4.1), two measurements form two equations

$$
\begin{aligned}
& \mathrm{X} \cos \theta_{0}=\phi_{0}+\mathrm{N} \\
& \mathrm{X} \cos \theta_{1}=\phi_{1}+\mathrm{N}+\mathrm{N}_{0}
\end{aligned}
$$

where the $\theta_{1}$ and $\phi_{1}$ are satellite elevation angle and phase difference at second measurement, $\mathrm{N}_{0}$ is wavelength integer change which has been accounted since initial measurement. All of the three parameters are known. So with one variable $\mathrm{X}$, and one variable $\mathrm{N}$, the solution can be solved. We put the equations in two dimensional matrix form.

$$
\left[\phi_{0}, \phi_{1}+\mathrm{N}_{0}\right]^{\mathrm{T}}=\left[\cos \theta_{0}, 1 ; \cos \theta_{1}, 1\right][\mathrm{X},-\mathrm{N}]^{\mathrm{T}} .
$$

From Eq. (4.3), we can see that the solution for $\mathrm{X}$ and $\mathrm{N}$ is based on $\left[\cos \theta_{0}, 1 ; \cos \theta_{1}, 1\right]$ being invertible. The matrix, which is the factor of Dilution of Precision, is decided by the geometric parameters. It affects the accuracy of the final solution. In order to get a good solution, we maximize the difference between 
$\cos \theta_{0}$ and $\cos \theta_{1}$. This means that we have to wait for the satellite to travel to a maximum usable elevation angle. Thus, static precision surveying has two disadvantages. In the first place, the primary and reference receivers must remain stationary. Secondly, it is very time consuming.

\section{CONTINUOUS PHASE TRACKING}

The continuous phase tracking method has been used by the other navigation systems long before GPS. The concept is very straight forward. Before surveying, the reference receiver and the primary receiver are put together and have the phase difference measurement calibrated. Or phase difference measurement of the reference receiver and the primary receiver is calibrated at the two surveyed locations. After the surveying starts, the primary receiver accounts for the phase difference change. The drawback of this method is apparent. In the first place, it is not flexible. The two receivers must be initially calibrated and recalibrated each time when the tracking of phase change is lost. Secondly, the phase change has to be continuously tracked. This requirement excludes many applications. That is why this method has been mainly used in ocean surveying or open area (desert) surveying where the continuously phase tracking is possible. 


\section{CHAPTER V}

\section{REVIEW OF CONDITIONAL MEAN AND MULTIPLE MODEL ESTIMATION ALGORITHM}

\section{THE CONDITIONAL MEAN AS THE BEST ESTIMATE[6]}

The following derivation serves as preparation for the theory for Multiple Model Estimation Algorithm. We first show that if we choose as our estimate the mean of $\mathrm{X}_{\mathrm{k}}$ conditioned on the available measurement stream, this estimate will minimize the mean-square error. In the following derivation, we temporarily drop the $\mathrm{k}$ subscripts for simplicity. And the measurement stream $\mathrm{Z}_{0}, \mathrm{Z}_{1}, \ldots, \mathrm{Z}_{\mathrm{k}}$ is represented as $\mathrm{Z}^{*}$. We first write the mean-square estimation error of $\mathrm{X}$, conditioned on $\mathrm{Z}^{*}$, as

$$
\begin{aligned}
E\left[\left(X-X^{\wedge}\right)^{\mathrm{T}}\left(X-X^{\wedge}\right) \mid Z^{*}\right]= & E\left(X^{T} X \mid Z^{*}\right)-E\left(X^{T} \mid Z^{*}\right) X^{\wedge} \\
& -X^{\wedge} \mathrm{T} E\left(X \mid Z^{*}\right)+X^{\wedge} X^{\wedge}
\end{aligned}
$$

where the $\mathrm{X}^{\wedge}$ is the best estimate of $\mathrm{X}$. Factoring $\mathrm{X}^{\wedge}$ away from the expectation operator in the Eq. (5.1) is justified since $\mathrm{X}^{\wedge}$ is a function of $\mathrm{Z}^{*}$, which is the conditioning on the random variable $\mathrm{X}$. We now complete the square of the last three terms in Eq. (5.1) and obtain

$$
\mathrm{E}\left[\left(X-X^{\wedge}\right)^{\mathrm{T}}\left(X-X^{\wedge}\right) \mid Z^{*}\right]=E\left(X^{T} X \mid Z^{*}\right)+
$$




$$
\begin{gathered}
{\left[X^{\wedge}-E\left(X \mid Z^{*}\right)\right]^{\mathrm{T}}\left[X^{\wedge}\right.} \\
\left.-E\left(X \mid Z^{*}\right)\right]-E\left(X^{T} \mid Z^{*}\right) E\left(X \mid Z^{*}\right) .
\end{gathered}
$$

Clearly, the first and last terms on the right side of Eq. (5.2) do not depend on our choice of the estimate $\mathrm{X}^{\wedge}$. Therefore, in our search among the admissible estimators (both linear and nonlinear), it should be clear that the best we can do is to force the middle term to be zero. So we let

$$
X^{\wedge}=E\left(X_{k} \mid Z_{k}^{*}\right)
$$

where we have now reinserted the $\mathrm{k}$ subscripts. We have tacitly assumed here that we are dealing with the filter problem, but a similar line of reasoning would also apply to the predictive and smoothed estimates of the $\mathrm{X}$ process.

Eq. (5.3) now provides us with a general formula for finding the estimator that minimizes the mean-square error. It is especially useful in the Gaussian case because it enables us to write out an explicit expression for the optimal estimate in recursive form. Thus, we will assume Gaussian statistics throughout from now on. We will further assume that we have an optimal prior estimate of $\mathrm{X}^{\wedge}$ denoted as $\mathrm{X}^{\wedge}$ and its associated error covariance $\mathrm{P}_{\mathrm{k}}^{-}$. Now, at this point we will stretch our notation somewhat and let $X_{k}$ denote the $X$ random variable at $t=k$ conditioned on the measurement stream $\mathrm{Z}_{\mathrm{k}-1}{ }^{*}$. We know that the form of the probability density of $X_{k}$ is then

$$
\mathrm{f}_{\mathrm{xk}} \sim \mathrm{N}\left(\mathrm{X}_{\mathrm{k}}^{\wedge}, \mathrm{P}_{\mathrm{k}}^{-}\right) \text {. }
$$

From our measurement model we know that $\mathrm{X}_{\mathrm{k}}$ is related to $\mathrm{Z}_{\mathrm{k}}$ by

$$
\mathrm{Z}_{\mathrm{k}}=\mathrm{H}_{\mathrm{k}} \mathrm{X}_{\mathrm{k}}+\mathrm{V}_{\mathrm{k}} \text {. }
$$


Therefore, we can immediately write the density function for $Z_{k}$ as

$$
\mathrm{f}_{2 \mathrm{k}} \sim \mathrm{N}\left(\mathrm{H}_{\mathrm{k}} \mathrm{X}_{\mathrm{k}}^{\wedge}, \mathrm{H}_{\mathrm{k}} \mathrm{P}_{\mathrm{k}}^{-} \mathrm{H}_{\mathrm{k}}^{\mathrm{T}}+\mathrm{R}_{\mathrm{k}}\right)
$$

The above equations is based on the condition of $\mathrm{Z}_{\mathrm{k}-1}{ }^{*}$. Also, from Eq. (5.5) we can write out the form for the conditional density of $Z_{k}$, given $X_{k}$. It is

$$
f_{z k \mid x k} \sim N\left(H_{k} X_{k}, R_{k}\right) \text {. }
$$

Finally, we can now use Bayes formula and write

$$
\mathrm{f}_{\mathrm{xk} \mid \mathrm{zk}}=\left(\mathrm{f}_{\mathrm{zk} \mid \mathbf{x k}} \mathrm{f}_{\mathrm{xk}}\right) / \mathrm{f}_{\mathrm{zk}} \cdot
$$

where the terms on the right side of the equation are given by Eqs. (5.4), (5.6), and (5.7). The $X_{k}$ is conditioned on $Z_{0}, Z_{1}, Z_{2} \ldots, Z_{k-1}$. Thus, the density function on the left side of Eq. (5.8) is actually the density of the random variable $\mathrm{X}_{\mathrm{k}}$, conditioned on the whole measurement stream up through $Z_{k}$. Thus we will change the notation slightly and rewrite Eq. (5.8) as

$$
\begin{aligned}
\mathrm{f}_{\mathrm{xk} \mid \mathrm{zk}}= & {\left[\left[\mathrm{N}\left(\mathrm{H}_{\mathrm{k}} \mathrm{X}_{\mathrm{k}}, \mathrm{R}_{\mathrm{k}}\right)\right]\left[\mathrm{N}\left(\mathrm{X}_{\mathrm{k}}^{\wedge}, \mathrm{P}_{\mathrm{k}}^{-}\right)\right]\right] /\left[\mathrm { N } \left(\mathrm{H}_{\mathrm{k}} \mathrm{X}_{\mathrm{k}}^{\wedge},\right.\right.} \\
& \left.\left.\mathrm{H}_{\mathrm{k}} \mathrm{P}_{\mathrm{k}}^{-} \mathrm{H}_{\mathrm{k}}^{\mathrm{T}}+\mathrm{R}_{\mathrm{k}}\right)\right]
\end{aligned}
$$

where it implied that we substitute the indicated normal functional expressions into the right side of the equation. This is a routine matter now to make the appropriate substitutions in Eq. (5.9) and determine the mean and covariance by inspection of the exponential term. The resulting mean and covariance for $\mathrm{X}_{\mathrm{k}} \mid \mathrm{Z}_{\mathrm{k}}{ }^{*}$ are

$$
\begin{aligned}
& \text { Mean }=X_{k}^{\wedge}+P_{k}^{-} H_{k}^{T}\left(H_{k} P_{k}^{-} H_{k}^{T}+R_{k}\right)^{-1}\left(Z_{k}-H_{k} X_{k}^{\wedge}\right) \\
& \text { Covariance }=\left[\left(P_{k}^{-}\right)^{-1}+H_{k}{ }^{T} R_{k-1} H_{k}\right]^{-1} .
\end{aligned}
$$

Note that the expression for the mean is identical to the optimal estimate by the 
Kalman filter. Actually the conditional mean as the best estimate is the same thing as Kalman filter. It is just interpreted in another way.

\section{MULTIPLE MODEL ESTIMATION ALGORITHM[6]}

In the usual Kalman filter we assume that all of the process parameters, $F_{k}$, $H_{k}, R_{k}$, and $Q_{k}$, are known. They may vary with time (index $k$ ) and we assume that the nature of the variation is known. So we still can apply the Kalman filter with changing parameters. But in actual process, because of inadequate prior test data about the process, some parameter might be expected to change slowly with time, and the exact nature of the change is not predictable. In such cases, it is highly desirable to design the filter to be self-learning, so that it can adapt itself to the situation at hand, whatever that might be. This problem has been first addressed by D.T. Magill. The Magill's filter is not just one filter, but a whole bank of Kalman filters running in parallel. Because of the parallel bank of filters, this scheme also goes under the name Multiple Model Estimation Algorithm (MMEA). We will now proceed to the derivation that leads to the bank of parallel filters.

The desired estimator is the conditional mean given by

$$
\mathrm{X}_{\mathrm{k}}=\int_{\mathrm{x}} \mathrm{XP}\left(\mathrm{X} \mid \mathrm{Z}_{\mathrm{k}}^{*}\right) \mathrm{dX}
$$

where $\mathrm{Z}_{\mathrm{k}}{ }^{*}$ denotes all the measurements up to and including time $\mathrm{t}=\mathbf{k}$, and $\mathrm{P}\left(\mathrm{X} \mid \mathrm{Z}_{\mathrm{k}}{ }^{*}\right)$ is the probability density function of $\mathrm{X}_{\mathrm{k}}$ with the conditioning shown in 
parentheses. The indicated integration is over the entire $\mathrm{X}$ space. If the $\mathrm{X}$ and $\mathrm{Z}$ processes are Gaussian, the estimate will be optimal by criterion of least-meansquare. We now assume that some parameter of the process, say $\alpha$, is unknown to the observer, and that this parameter is a random variable. Thus, on any particular sample run it will be an unknown constant with a known statistical distribution. Now we rewrite the Eq. (5.12) in the form as

$$
\mathrm{X}_{\mathrm{k}}=\int_{\mathrm{x}} \mathrm{X} \int_{\alpha} \mathrm{P}\left((\mathrm{X}, \alpha) \mid \mathrm{Z}_{\mathrm{k}}{ }^{*}\right) \mathrm{d} \alpha \mathrm{dX} \text {. }
$$

The joint density in Eq. (5.13) can be written as

$$
\mathrm{P}\left((\mathrm{X}, \alpha) \mid \mathrm{Z}_{\mathrm{k}}^{*}\right)=\mathrm{P}\left(\mathrm{X} \mid\left(\alpha, \mathrm{Z}_{\mathrm{k}}^{*}\right)\right) \mathrm{P}\left(\alpha \mid \mathrm{Z}_{\mathrm{k}}^{*}\right) .
$$

Substituting Eq. (5.13) and Eq. (5.14) and interchanging the order of integration leads to

$$
\mathrm{X}_{\mathrm{k}}{ }_{\mathrm{k}}=\int_{\alpha} \mathrm{P}\left(\alpha \mid \mathrm{Z}_{\mathrm{k}}^{*}\right) \int_{\mathrm{x}} \mathrm{XP}\left(\mathrm{X} \mid\left(\alpha, \mathrm{Z}_{\mathrm{k}}^{*}\right) \mathrm{dXd} \alpha\right.
$$

The inner integral is the usual Kalman filter estimate for a given $\alpha$. This is denoted by $\mathrm{X}_{\mathrm{k}}(\alpha)$ where $\alpha$ shown in parentheses is intended as a reminder that there is $\alpha$ dependence. Eq. (5.15) now can be rewritten as

$$
\mathrm{X}_{\mathrm{k}}=\int_{\alpha} \mathrm{X}_{\mathrm{k}}(\alpha) \mathrm{P}\left(\alpha \mid \mathrm{Z}_{\mathrm{k}}^{*}\right) \mathrm{d} \alpha \text {. }
$$

For the discrete random variable equivalent to Eq. (5.16) would be

$$
\mathrm{X}_{\mathrm{k}}^{\wedge}=\sum \mathrm{X}_{\mathrm{k}}^{\wedge}\left(\alpha_{\mathrm{i}}\right) \mathrm{P}\left(\alpha_{\mathrm{i}} \mid \mathrm{Z}_{\mathrm{k}}^{*}\right)
$$

where the summation is over $\alpha_{i}, i=1, \ldots \mathrm{L}$, and the $\mathrm{P}\left(\alpha_{\mathrm{i}} \mid \mathrm{Z}_{\mathrm{k}}{ }^{*}\right)$ is the discrete probability for $\alpha_{i}$, conditioned on the measurement sequence $\mathrm{Z}_{\mathrm{k}}{ }^{*}$. From now on, we will concentrate on the discrete form in this paper.

Eq. (5.17) simply says that the optimal estimate is a weighted sum of 
Kalman filter estimates with each Kalman filter operating with a separate assumed value of $\alpha$.

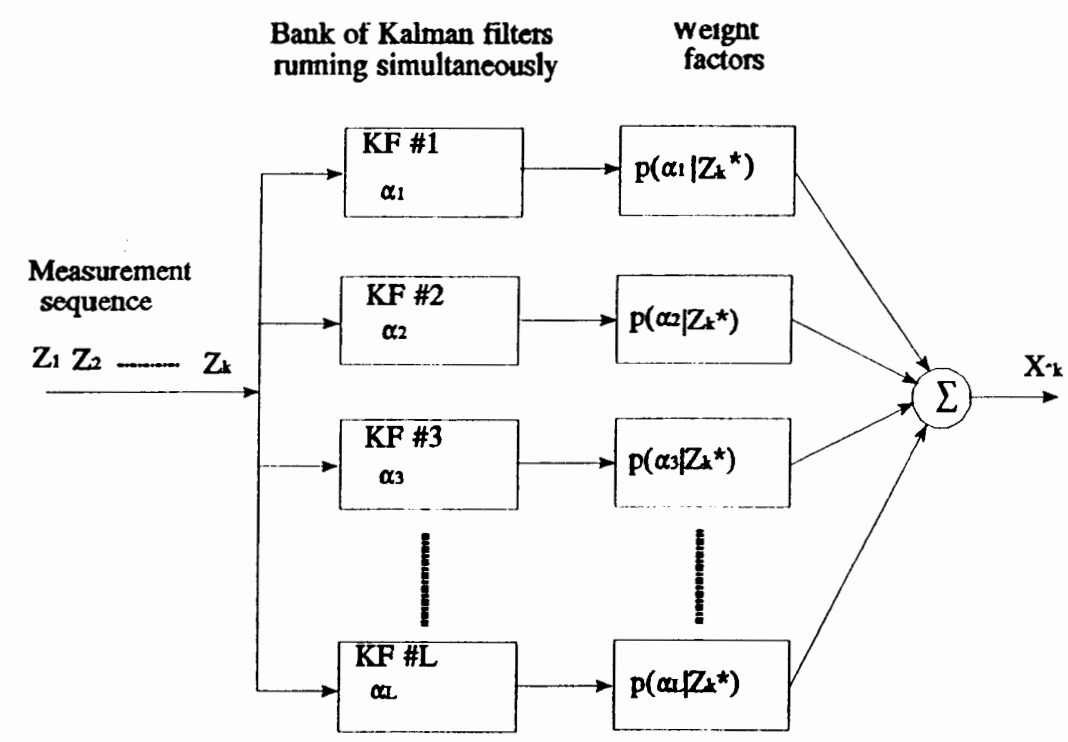

Figure 7. Bank of Kalman Filters in Parallel.

This is shown in Figure 7. The problem now reduces to one of determining the weight factors $\mathrm{P}\left(\alpha_{1} \mid \mathrm{Z}_{\mathrm{k}}{ }^{*}\right), \mathrm{P}\left(\alpha_{2} \mid \mathrm{Z}_{\mathrm{k}}{ }^{*}\right), \ldots, \mathrm{P}\left(\alpha_{\mathrm{L}} \mid \mathrm{Z}_{\mathrm{k}}{ }^{*}\right)$. These change with each recursive step as the measurement process evolves in time. Presumably, as more and more measurements become available, we learn more about the state of the process and the unknown parameter $\alpha$.

We now turn to the matter of finding the weight factors indicated in Figure 7. We use the Bayes's rule: 


$$
\mathrm{P}\left(\alpha_{\mathrm{i}} \mid \mathrm{Z}_{\mathrm{k}}^{*}\right)=\mathrm{P}\left(\mathrm{Z}_{\mathrm{k}}^{*} \mid \alpha_{\mathrm{i}}\right) \mathrm{P}\left(\alpha_{\mathrm{i}}\right) / \mathrm{P}\left(\mathrm{Z}_{\mathrm{k}}^{*}\right)
$$

and

$$
\begin{aligned}
\mathrm{P}\left(\mathrm{Z}_{\mathrm{k}}{ }^{*}\right) & =\sum \mathrm{P}\left(\mathrm{Z}_{\mathrm{k}}{ }^{*}, \alpha_{\mathrm{j}}\right) \\
& =\sum \mathrm{P}\left(\mathrm{Z}_{\mathrm{k}}{ }^{*} \mid \alpha_{\mathrm{j}}\right) \mathrm{P}\left(\alpha_{\mathrm{j}}\right) .
\end{aligned}
$$

The summation is over $\alpha_{\mathrm{j}}, \mathrm{j}=1$ to L. Combining the Eq. (5.19) and Eq. (5.18) we get the result

$$
\begin{gathered}
\mathrm{P}\left(\alpha_{\mathrm{i}} \mid \mathrm{Z}_{\mathrm{k}}{ }^{*}\right)=\left[\mathrm{P}\left(\mathrm{Z}_{\mathrm{k}}{ }^{*} \mid \alpha_{\mathrm{i}}\right) \mathrm{P}\left(\alpha_{\mathrm{i}}\right)\right] / \sum\left[\mathrm{P}\left(\mathrm{Z}_{\mathrm{k}}{ }^{*} \mid \alpha_{\mathrm{j}}\right) \mathrm{P}\left(\alpha_{\mathrm{j}}\right)\right] \\
\mathrm{j}, \mathrm{i}=1,2, \ldots \mathrm{L} .
\end{gathered}
$$

The distribution of $\mathrm{P}\left(\alpha_{\mathrm{i}}\right)$ is resumed to be known, so it remains to determine $\mathrm{P}\left(\mathrm{Z}_{\mathrm{k}}{ }^{*} \mid \alpha_{\mathrm{i}}\right)$ in Eq. (5.20). So we write $\mathrm{P}\left(\mathrm{Z}_{\mathrm{k}}{ }^{*} \mid \alpha_{\mathrm{i}}\right)$ as a product of conditional density functions. Temporarily we drop the $\alpha_{i}$ conditioning to save the writing. So we have

$$
\begin{aligned}
\mathrm{P}\left(\mathrm{Z}_{\mathrm{k}}^{*}\right) & =\mathrm{P}\left(\mathrm{Z}_{\mathrm{k}}, \mathrm{Z}_{\mathrm{k}-1}, \ldots \mathrm{Z}_{0}\right) \\
& =\mathrm{P}\left(\left(\mathrm{Z}_{\mathrm{k}}, \mathrm{Z}_{\mathrm{k}-1}, \ldots \mathrm{Z}_{1}\right) \mid \mathrm{Z}_{0}\right) \mathrm{P}\left(\mathrm{Z}_{0}\right) \\
& =\mathrm{P}\left(\left(\mathrm{Z}_{\mathrm{k}} \mid\left(\mathrm{Z}_{\mathrm{k}-1}, \mathrm{Z}_{\mathrm{k}-2}, . . \mathrm{Z}_{0}\right) \mathrm{P}\left(\mathrm{Z}_{\mathrm{k}-1} \mid \mathrm{Z}_{\mathrm{k}-2}, \ldots \mathrm{Z}_{0}\right)\right.\right. \\
& \ldots \mathrm{P}\left(\mathrm{Z}_{1} \mid \mathrm{Z}_{0}\right) \mathrm{P}\left(\mathrm{Z}_{0}\right) \\
& \mathrm{k}=1,2,3, \ldots
\end{aligned}
$$

The first term in the product string of Eq. (5.21) is $\mathrm{P}\left(\mathrm{Z}^{\wedge}{ }_{\mathrm{k}}\right)$, and that the remaining product is $\mathrm{P}\left(\mathrm{Z}_{\mathrm{k}-1}{ }^{*}\right)$. Thus we can rewrite $\mathrm{Eq}$. (5.21) in the form

$$
\mathrm{P}\left(\mathrm{Z}_{\mathrm{k}}{ }^{*}\right)=\mathrm{P}\left(\mathrm{Z}_{\mathrm{k}}{ }^{-}\right) \mathrm{P}\left(\mathrm{Z}_{\mathrm{k}-1}{ }^{*}\right)
$$

Under the assumption that $\mathrm{X}$ and $\mathrm{Z}$ is Gaussian process, and $\mathrm{Z}_{\mathrm{k}}{ }^{*}$ is a sequence of scalar measurements $Z_{0}, Z_{1}, Z_{2}, \ldots Z_{k}$, and now we put the $\alpha_{i}$ back, the 
Eq. (5.22) then becomes

$$
\begin{aligned}
\mathrm{P}\left(\mathrm{Z}_{\mathrm{k}}{ }^{*} / \alpha_{\mathrm{i}}\right)= & {\left[\operatorname { e x p } \left[-\left(\mathrm{Z}_{\mathrm{k}}-\mathrm{H}_{\mathrm{k}} \mathrm{X}^{\wedge}{ }^{-}\right)^{2} /\left(2 \left(\mathrm{H}_{\mathrm{k}} \mathrm{P}_{\mathrm{k}}{ }^{-\mathrm{H}_{\mathrm{k}}{ }^{\mathrm{T}}}\right.\right.\right.\right.} \\
& \left.\left.\left.+\mathrm{R}_{\mathrm{k}}\right)\right] /\left[(2 \pi)^{1 / 2}\left(\mathrm{H}_{\mathrm{k}} \mathrm{P}_{\mathrm{k}}-\mathrm{H}_{\mathrm{k}}^{\mathrm{T}}+\mathrm{R}_{\mathrm{k}}\right)^{1 / 2}\right]\right] \mathrm{P}\left(\mathrm{Z}_{\mathrm{k}-1}{ }^{*} / \alpha_{\mathrm{i}}\right) \\
& \mathrm{k}=1,2,3, \ldots
\end{aligned}
$$

The Eq. (5.23) is on conditioning of $\alpha_{\mathrm{i}}$. For each different $\alpha_{\mathrm{i}}$, it will yield a different $\mathrm{P}\left(\mathrm{Z}_{\mathrm{k}}{ }^{*}\right)$. The $\alpha_{\mathrm{i}}$ can affect the $\mathrm{Z}_{\mathrm{k}}, \mathrm{H}_{\mathrm{k}}, \mathrm{P}_{\mathrm{k}}, \mathrm{R}_{\mathrm{k}}$, and $\mathrm{X}^{\wedge}{ }_{\mathrm{k}}$ simultaneously or individually. By examining the Eq. (5.20), the $\mathrm{P}\left(\mathrm{Z}_{\mathrm{k}^{*}} / \alpha_{\mathrm{i}}\right)$ is the only term that decide if $\mathrm{P}\left(\alpha_{\mathrm{i}} \mid \mathrm{Z}_{\mathrm{k}}{ }^{*}\right)$ will approach to 1 or 0 . So by calculating the $\mathrm{P}\left(\mathrm{Z}_{\mathrm{k}}{ }^{*} / \alpha_{\mathrm{i}}\right)$ we will be able to determine the right hypothesis.

After determining the hypothesis, the remaining part of the Multiple Model Estimation Algorithm is the regular Kalman filter[3]. 


\section{CHAPTER VI}

\section{APPLICATION OF MMEA IN PRECISION POSITIONING}

\section{DYNAMIC STATE PROCESS FOR GPS OBSERVER}

In the most basic description of GPS positioning observer, we need to have at least three dimensions of freedom for position and one degree of freedom for time. In the random process, the time error is related to the characteristic of the receiver clock. And the positioning error state is depend on the observer's dynamics. Generally speaking, the two process of the time and the position errors are independent (Unless the physical stress on the oscillator or doppler effect). A random walk model for the observer is shown in Figure 8. This is the most basic model to estimate position and time.

The random walk model is a linearized Kalman filter state vector which usually consists of three position error states and two time error states, which are time error and time drift rate. The Kalman filter error states are referred to the nominal fixed position and time. This model usually is called the Position model. The random walk model[6] is usually good for the stationary or the low dynamic GPS observers. When the observer is not such case but moving with nearly constant velocity, we will have the integrated random walk model as shown in 
Figure 9 which is also called Position-Velocity model[6].

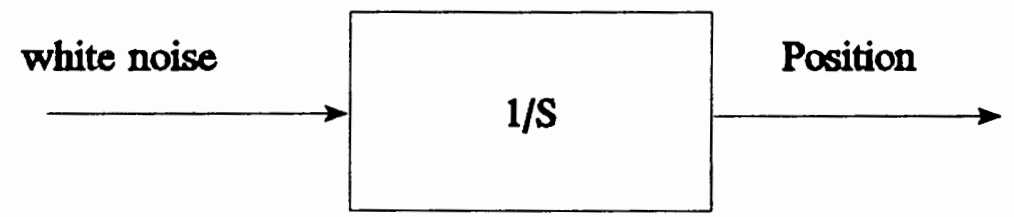

Figure 8. Random Walk Model of GPS Observer.

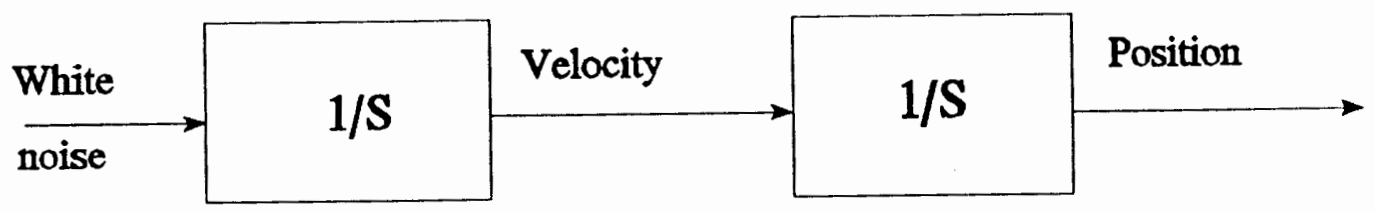

Figure 9. Integrated Random Walk Model of GPS Observer. 
Suppose that the GPS observer is in a more severe dynamic situation and the assumption of nearly constant velocity does not hold. A further improved model is shown in Figure 10 which is also called Position-Velocity-Acceleration model[6].

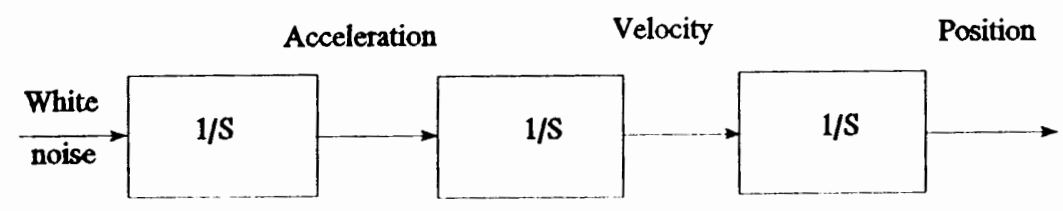

Figure 10. Position-Velocity-Acceleration Model of High Dynamic GPS Observer.

In this paper, for the purpose of simplicity and illustration, we choose the random walk model. Also, we assume that there is no time error, and we only work out the solution in one dimension. But it can be easily propagated to three dimensions and the proposed method does apply to all the dynamic models with time error.

In the one dimensional discrete random walk model, it can be described as

$$
\mathrm{X}_{\mathrm{k}+1}=\mathrm{X}_{\mathrm{k}}+\mathrm{W}_{\mathrm{k}}
$$

where the $\mathrm{W}_{\mathrm{k}}$ is random noise, and $\mathrm{X}_{\mathrm{k}}$ is the state (position) error referred to the nominal position. 


\section{SOLUTION OF AMBIGUITY INTEGER BY MMEA}

In Figure 11, the reference receiver and primary receiver have the capability of measuring the phase of a satellite signal relative to the local frequency standard (GPS receiver can output the phase measurement from the Costa Phase Locked Loop). For simplicity, we assume the frequency standard at the Point $A$ and Point $B$ is synchronized (i.e. no clock error). Now let $X_{0}$ be the measurement of distance between point A and point B by Differential GPS, and $X_{k}$ be a small error between the true distance $X_{0}+X_{k}$ at point $C$ and the point $B$.

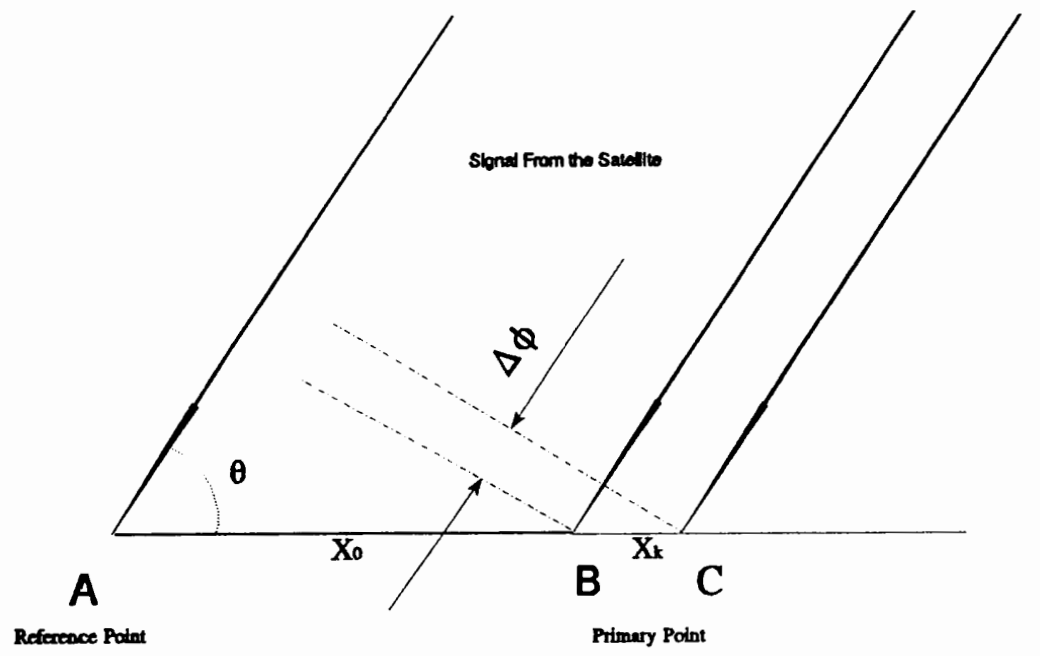

Figure 11. Error Phase Difference $X_{k}$.

The phase difference of the received carrier at $\mathrm{B}$ and $\mathrm{C}$ has relation with $\mathrm{X}_{\mathrm{k}}$ as the follow 


$$
\Delta \phi_{\mathrm{k}}=\mathrm{X}_{\mathrm{k}} \cos \theta / \lambda
$$

where $\lambda$ is wavelength and $\Delta \phi_{\mathrm{k}}$ is phase difference between point $\mathrm{C}$ and point $\mathrm{B}$ measured in wavelengths. Because the $\Delta \phi_{\mathrm{k}}$ is measured between 0 to 1 wavelength plus an unknown initial integer $\mathrm{N}$, the actual measurements of the phase difference, denoted as $Z_{k}$, is $\Delta \phi_{k}$ minus the initial ambiguity integer. We assume that after $k=0$, the full wavelengths of $Z_{k}$ will be known. We rewrite the Eq. (6.2) as

$$
\begin{aligned}
\Delta \phi_{\mathrm{k}} & =\mathrm{Z}_{\mathrm{k}}-\mathrm{N} \\
& =\mathrm{X}_{\mathrm{k}} \cos \theta / \lambda .
\end{aligned}
$$

Considering the measurement noise, the Eq. (6.2) will be as

$$
\mathrm{Z}_{\mathrm{k}}=\mathrm{X}_{\mathrm{k}} \cos \theta / \lambda+\mathrm{N}+\mathrm{V}_{\mathrm{k}}
$$

where the $V_{k}$ is the measurement noise, and $N$ is ambiguity integer. At this point, we assume that the state transition model of variable $X_{k}$ is known. And if there was no initial ambiguity integer, the solution of this problem would be application of a routine Kalman filter.

From Chapter $\mathrm{V}$ we know that the ambiguity integer problem can be solved by the Multiple Model Estimation Algorithm. As shown in Figure 12, the ambiguity integer is modeled as the hypothesis of the MMEA. For simplicity, we take the integers value from $n$ to $-n$. In this scheme, the hypothesis only has the effects on the measurements. The bank of parallel Kalman filters actually have the same parameters, $F_{k}, H_{k}, Q_{k}, R_{k}, P_{k}^{-}$, and $K$, which are Kalman filter parameters. They take form as 


$$
\begin{aligned}
& \mathrm{Z}_{\mathrm{k}}=\mathrm{H}_{\mathrm{k}} \mathrm{X}_{\mathrm{k}}+\mathrm{V}_{\mathrm{k}} \\
& \mathrm{X}_{\mathrm{k}+1}=\mathrm{F}_{\mathrm{k}} \mathrm{X}_{\mathrm{k}}+\mathrm{W}_{\mathrm{k}} .
\end{aligned}
$$

And $\mathrm{Q}_{\mathrm{k}}=\operatorname{Cov}\left(\mathrm{W}_{\mathrm{k}}\right), \mathrm{R}_{\mathrm{k}}=\operatorname{Cov}\left(\mathrm{V}_{\mathrm{k}}\right)$, and $\mathrm{P}_{\mathrm{k}}^{-}$is covariance of best estimate of $\mathrm{X}_{\mathrm{k}}$ at time $\mathrm{K}-1$. In our case, $\mathrm{F}_{\mathrm{k}}=1$. This is computationally advantageous. Also it is especially important to on-line processing.

The first task in MMEA is to find out the right hypothesis by calculating the probability density as Eq. (5.20)

$$
\mathrm{P}\left(\mathrm{N} / \mathrm{Z}_{\mathrm{k}}{ }^{*}\right)=\left[\mathrm{P}\left(\mathrm{Z}_{\mathrm{k}}{ }^{*} \mid \mathrm{N}\right) \mathrm{P}(\mathrm{N})\right] / \sum\left[\mathrm{P}\left(\mathrm{Z}_{\mathrm{k}}{ }^{*} \mid \mathrm{m}\right) \mathrm{P}(\mathrm{m})\right]
$$

where the summation is over $m$ from $-n$ to $n . N$ is the hypothesis integer which takes value from $-n$ to $n$ for each test.

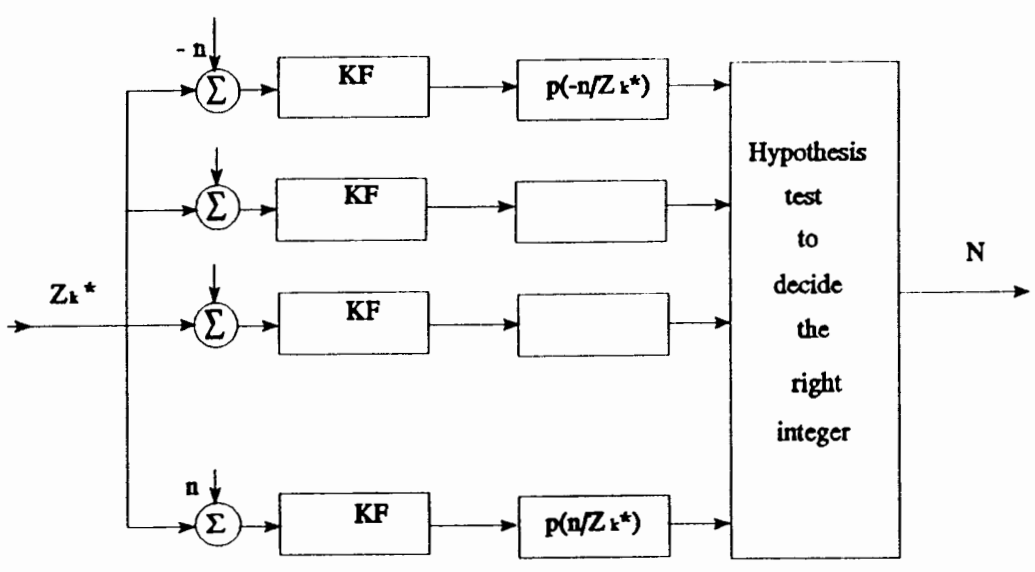

Figure 12. Parallel Filter Bank of the MMEA.

Now let study Eq. (6.6) to see which term will make a difference to $\mathrm{P}\left(\mathrm{N} / \mathrm{Z}_{\mathrm{k}}{ }^{*}\right)$ for each hypothesis. First of all, the denominator is same for all the $\mathrm{N}$. 
Also $\mathrm{P}(\mathrm{N})$ is a scaling factor that would not make a difference to the value of $\mathrm{P}\left(\mathrm{N} / \mathrm{Z}_{\mathrm{k}}{ }^{*}\right)$ between 1 or 0 . So the true or false hypothesis test of $\mathrm{P}\left(\mathrm{N} / \mathrm{Z}_{\mathrm{k}}{ }^{*}\right)$ is determined by the term $\mathrm{P}\left(\mathrm{Z}_{\mathrm{k}}{ }^{*} \mid \mathrm{N}\right)$. As shown in the Eq. (5.23),

$$
\begin{aligned}
\mathrm{P}\left(\mathrm{Z}_{\mathrm{k}}{ }^{*} \mid \mathrm{N}\right)= & {\left[\operatorname { e x p } \left[-\left(\mathrm{Z}_{\mathrm{k}}-\mathrm{H}_{\mathrm{k}} \mathrm{X}_{\mathrm{k}}{ }^{-}\right)^{2} /\left(2 \left(\mathrm{H}_{\mathrm{k}} \mathrm{P}_{\mathrm{k}}{ }^{-\mathrm{H}_{\mathrm{k}}{ }^{\mathrm{T}}}\right.\right.\right.\right.} \\
& \left.\left.\left.+\mathrm{R}_{\mathrm{k}}\right)\right] /\left[(2 \pi)^{1 / 2}\left(\mathrm{H}_{\mathrm{k}} \mathrm{P}_{\mathrm{k}}{ }^{-} \mathrm{H}_{\mathrm{k}}{ }^{\mathrm{T}}+\mathrm{R}_{\mathrm{k}}\right)^{1 / 2}\right]\right] \mathrm{P}\left(\mathrm{Z}_{\mathrm{k}-1}{ }^{*} / \mathrm{N}\right) \\
& \mathrm{k}=1,2,3, \ldots
\end{aligned}
$$

where is $\mathrm{N}$ only affect the value of $\mathrm{Z}_{\mathrm{k}}$. Thus we can determine which integer value is correct one. For the correct hypothesis integer, the normalized $\mathrm{P}\left(\mathrm{Z}_{\mathrm{k}}{ }^{*} / \mathrm{N}\right)$ will approach unity, while for the wrong hypothesis integers, they will doom to zeros. Once the $\mathrm{N}$ is determined, the optimal processing of the differential phase measurements will be a routine Kalman filtering.

The MMEA has some advantage comparing with other methods.

a, It does not require continuous observation of the satellite initially.

b, Kalman filter is recursive technique and has the potential of on-line operation.

c, Kalman filter has been used extensively in navigation and proved to be very efficient.

In next Chapter, we will report the results of computer simulation while considering the actual surveying environments. 


\section{CHAPTER VII}

\section{SIMULATION AND ANALYSIS OF THE RESULTS}

The simulation assumes the followings. The satellite and the surveying system are both in one dimension. The motion of the satellite that we use to measure its carrier phase is also in one dimension.

Finally,

. The initial satellite angle is $\pi / 3$.

. The satellite is moving down at $\pi / 6$ per hour.

. The hypothesis integer $\mathbf{N}=-10$ to 10 .

. The initial estimation error covariance $P_{0}^{-}=40 \mathrm{~cm}^{2}$.

. The $Q_{k}=36 \mathrm{~cm}^{2}$.

. The $R_{k}=4 \mathrm{~cm}^{2}$.

Figure 13 shows the simulated actual phase difference between the point $B$ and the point $C$ in solid line. Figure 14 shows the simulated measured phase difference between the point $\mathrm{B}$ and the point $\mathrm{C}$ with initial integer offset from the Figure 13 in broken line. Actually the key point of the paper is to find the ambiguity integer and then apply the Kalman filter.

Figure 15 shows the hypothesis test results. The normalized $\mathrm{P}\left(\mathrm{Z}_{\mathrm{k}}{ }^{*} / 4\right)$ conditioned on the correct hypothesis integer will approach unity after about 25 


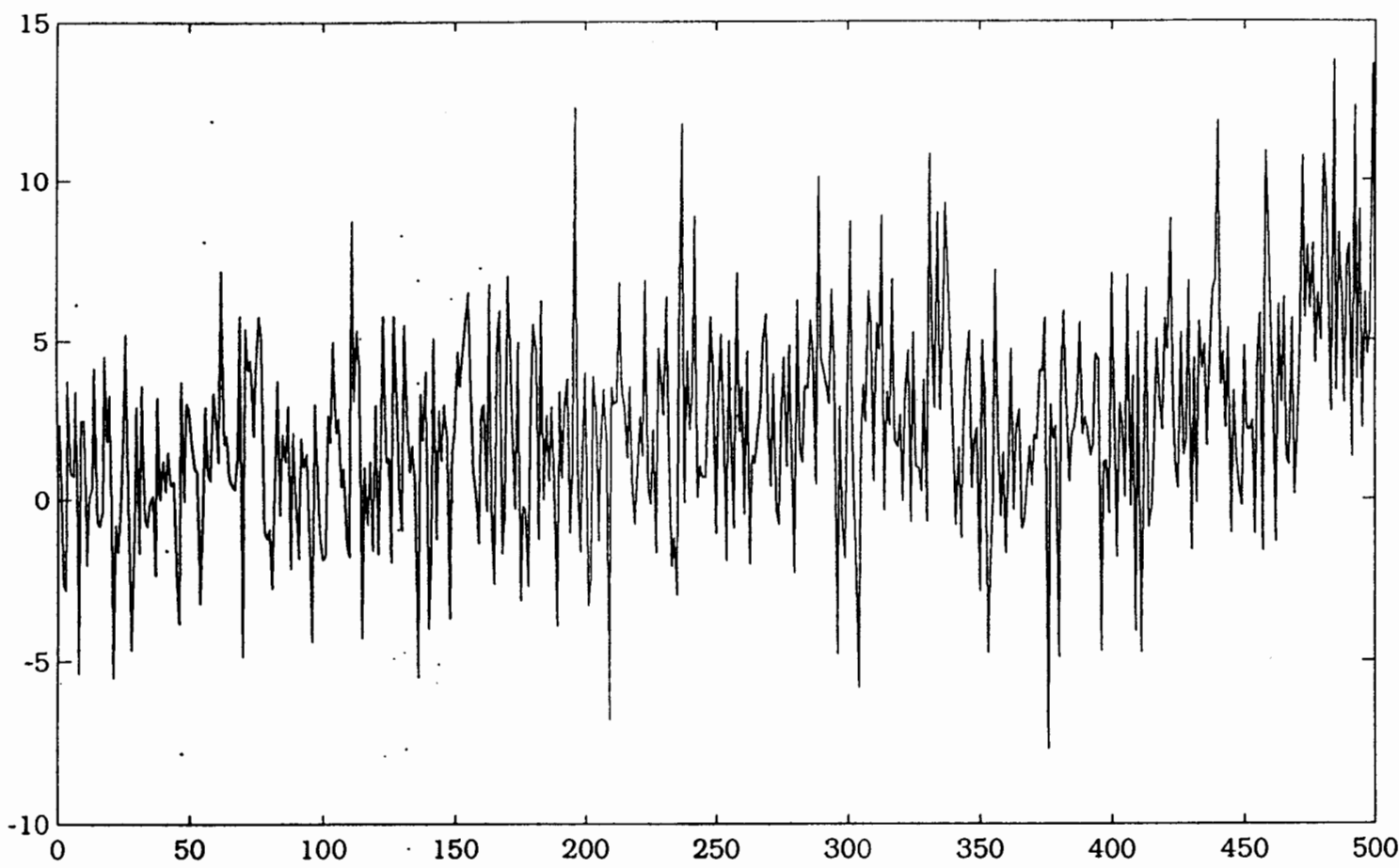

Figure 13. Actual Phase Difference.

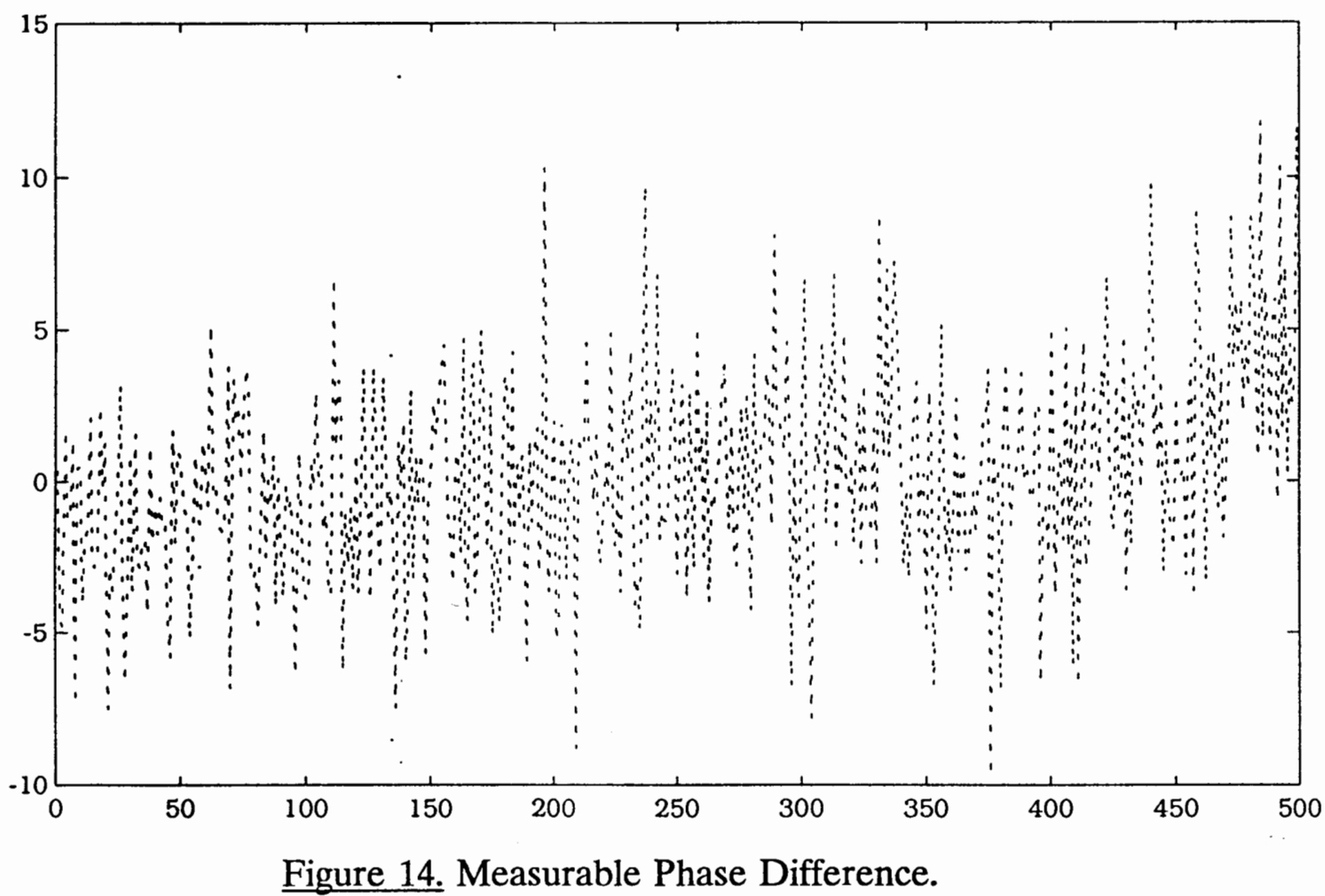




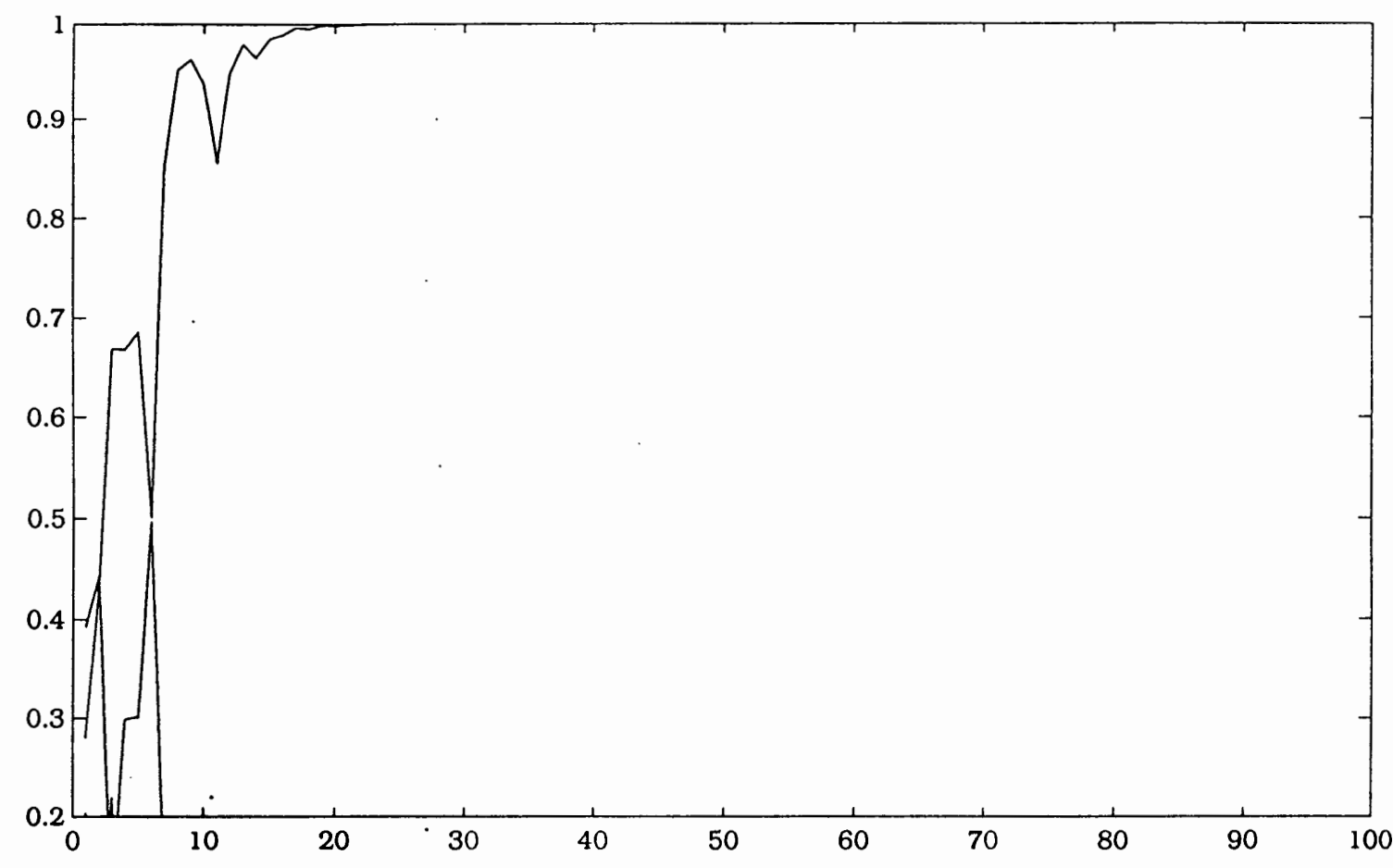

Figure 15. Ambiguity Integer Hypothesis Test I.

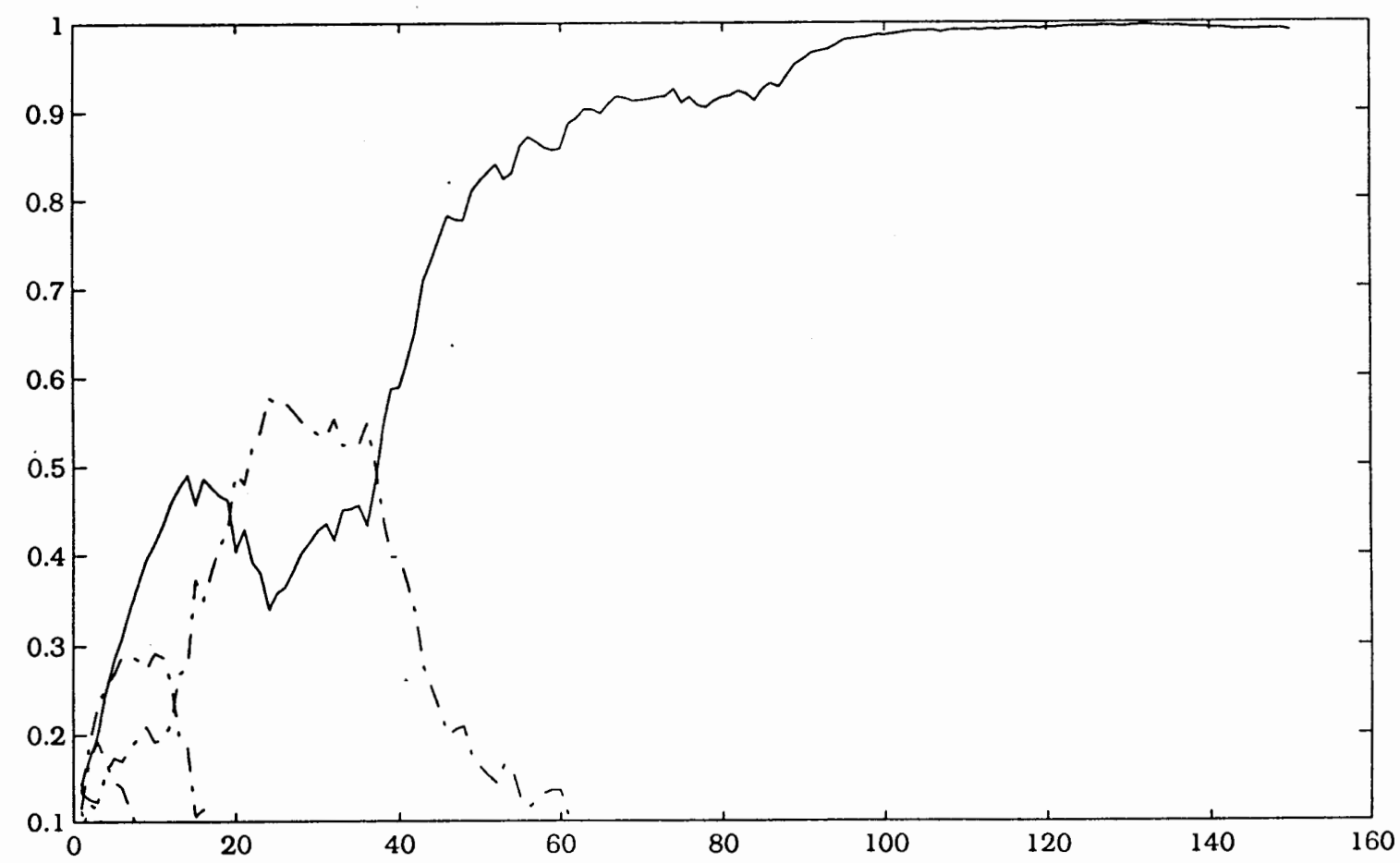

Figure 16. Ambiguity Integer Hypothesis Test II. 


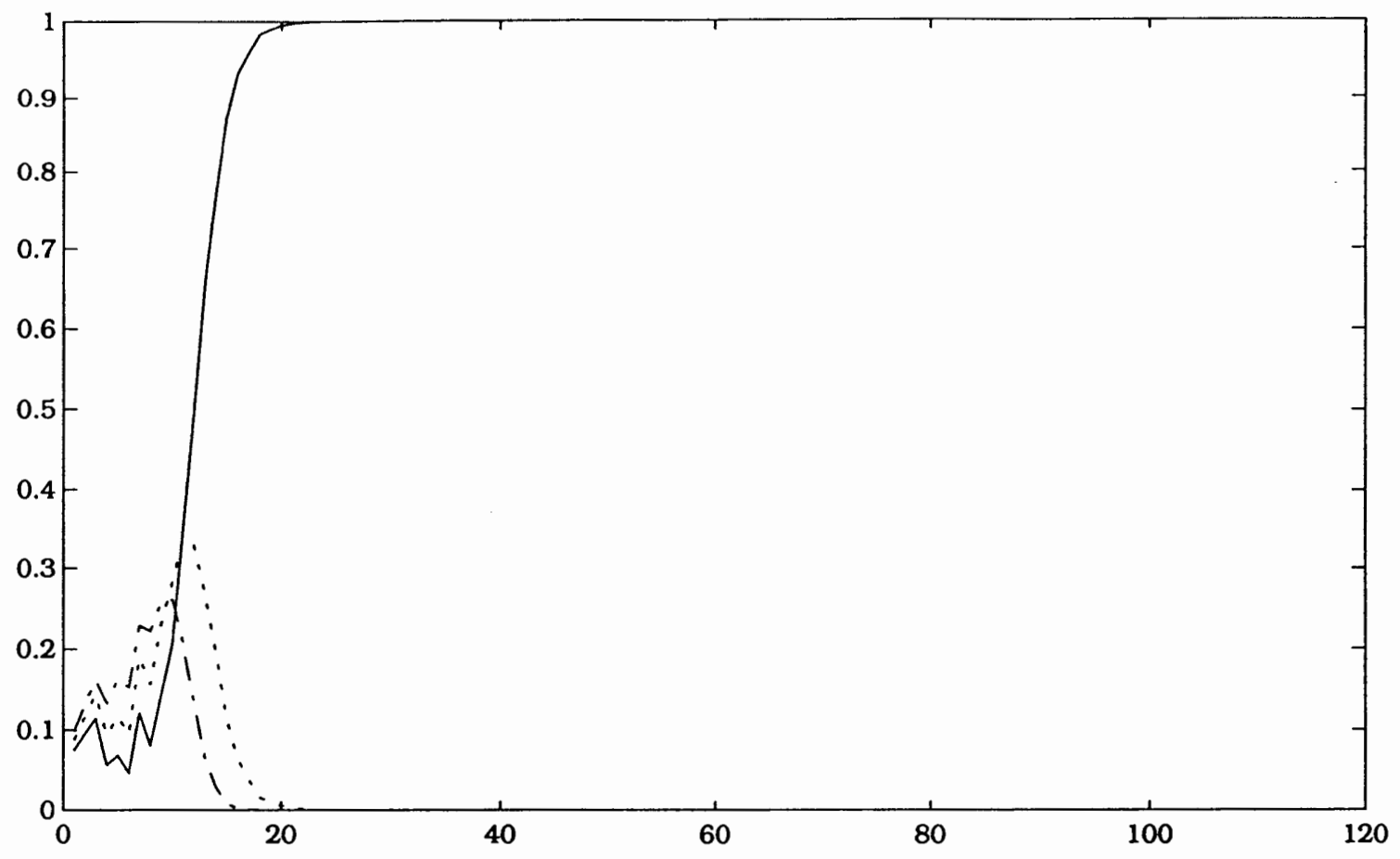

Figure 17. Ambiguity Integer Hypothesis Test III.

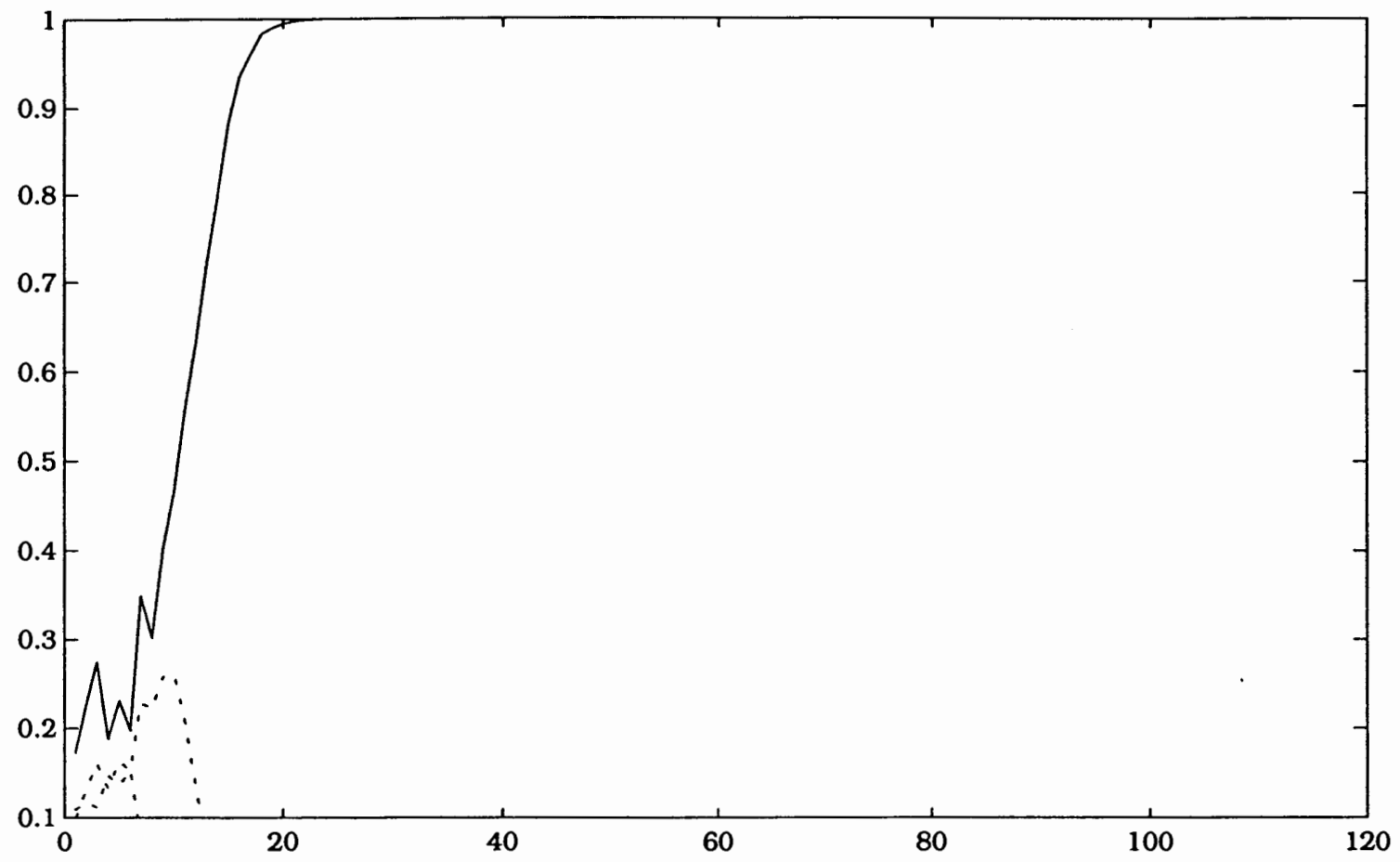

Figure 18. Ambiguity Integer Hypothesis Test IV. 

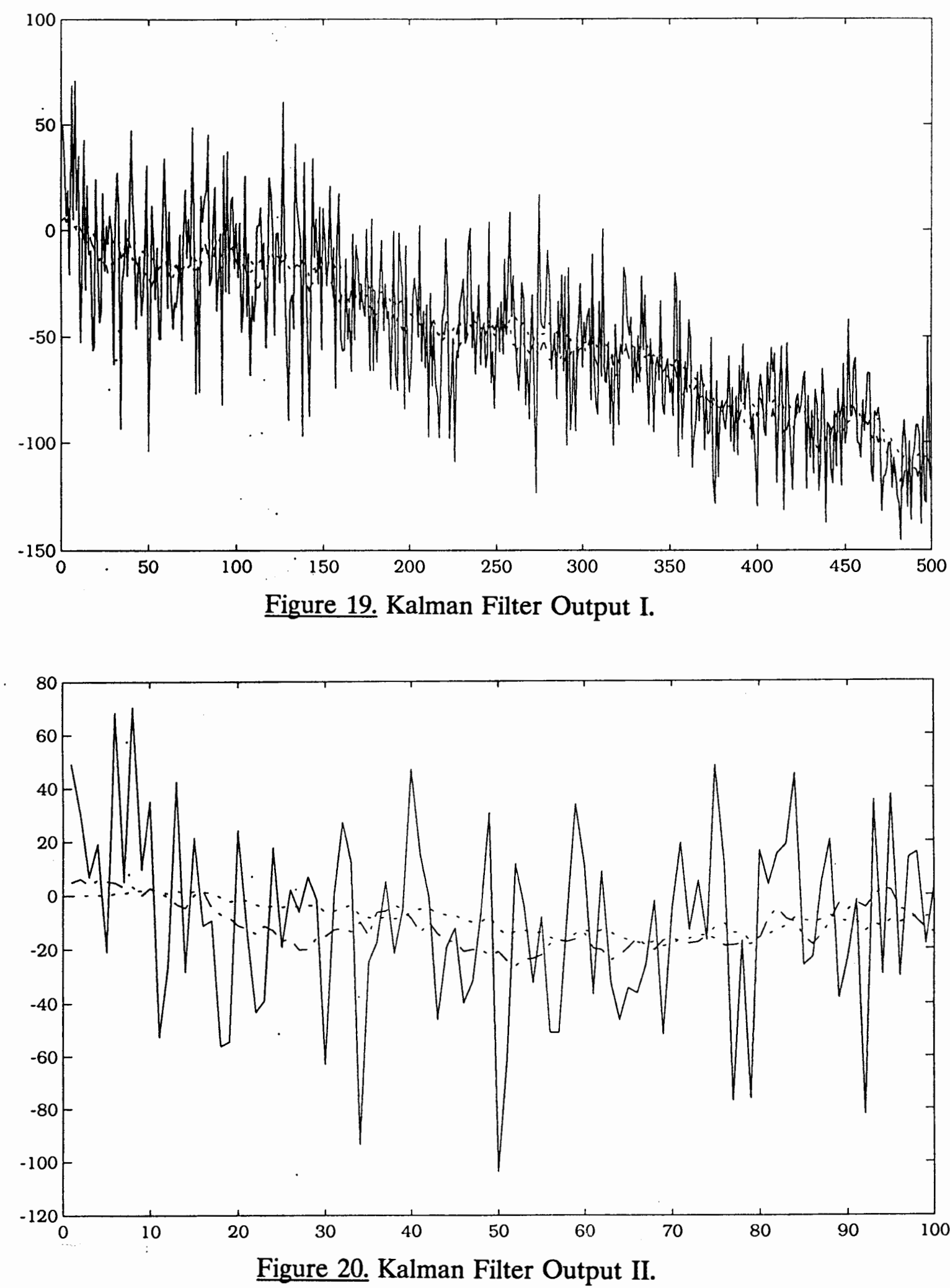
steps, while the normalized $\mathrm{P}\left(\mathrm{Z}_{\mathrm{k}}{ }^{*} \mid \mathrm{n}\right)$ when conditioned on the wrong hypothesis integers will approach zero. Figure 16 is a comparison test. We set $R_{k}=8 \mathrm{~cm}^{2}$. We can see that the normalized $\mathrm{P}\left(\mathrm{Z}_{\mathrm{k}}{ }^{*} \mid 6\right)$ approach to unity after 100 steps. This results agree with the mathematical derivation in Eq. (6.5) and Eq. (6.6), and

$$
\mathrm{P}\left(\mathrm{Z}_{\mathrm{k}} / \mathrm{n}\right) \sim \mathrm{N}\left(\mathrm{H}_{\mathrm{k}} \mathrm{X}_{\mathrm{k}}, \mathrm{H}_{\mathrm{k}} \mathrm{P}_{\mathrm{k}} \mathrm{H}_{\mathrm{k}}^{\mathrm{T}}+\mathrm{R}_{\mathrm{k}}\right)
$$

where $\mathrm{N}()$ is a normal distribution. That means that the larger the $\mathrm{R}_{\mathrm{k}}$ is, the larger the covariance is. Thus, $Z_{k}$ is more widely scattered around the mean $\mathrm{H}_{k} X_{k}$. In the Figure 16 , the $P\left(Z_{k} \mid 6\right)$ convene more slowly than $P\left(Z_{k} \mid 4\right)$ in Figure 15 . The $R_{k}$ is measurement noise which can be contributed from measurement of the phase at the both primary receiver and the reference receiver and the clock drift at the both receivers. Figure 17 and Figure 18 show the hypothesis test results when the hypothesis integer $\mathrm{N}$ is changed to -5 to 5 and -20 to 20 respectively. The range of the hypothesis integer is determined by the initial $\mathrm{P}_{0}^{-}$which is determined by the Differential GPS measurement accuracy. For our simulation case, we choose the $\mathrm{P}_{0}^{-}=40 \mathrm{~cm}^{2}$ (The sigma of the initial measurement accuracy). Because one hypothesis integer corresponds to one wavelength $(\lambda=19 \mathrm{~cm}), \mathrm{N}=4$ is about the two times the value of $P_{0}^{-}$which will cover the $94 \%$ of the probability of a successful hypothesis test. For $\mathrm{N}=5$, the probability will be about $98 \%$. When the $\mathrm{P}_{0}^{-}$changes, say it is ten times larger, in order to get the same probability coverage the value of $\mathrm{N}$ should also be increased by a factor of ten. Under the assumption that the $\mathrm{P}_{0}^{-}=40 \mathrm{~cm}^{2}$ and $\mathrm{N}=5$, there is still $2 \%$ probability that the true integer value is beyond the hypothesis integer test range. Supposed the true integer value 
is six which is larger than the range of hypothesis integer test, then the hypothesis integer test will falsely converge to the integer value of five which is the hypothesis integer upper limit. The true value may also be smaller than the lower limit of the hypothesis integer and falsely converge to this integer. If the result of hypothesis test is at the limit values, we shall reject the test and run hypothesis test again. If such a thing happens again, we conclude that the hypothesis integer value is not larger enough to accommodate the $\mathrm{P}_{0}^{-}$, and we increase the value of $\mathrm{N}$.

Theoretically, we can always choose a large enough $N$ to accommodate any $\mathrm{P}_{0}^{-}$ value in order to have a better than $95 \%$ of probability of a successful hypothesis test. The larger $\mathrm{P}_{0}^{-}$is, the larger $\mathrm{N}$. The larger $\mathrm{N}$ is, the longer time the Kalman filters take to calculate the filtered time series. In practical Differential GPS system, the $\mathrm{P}_{0}^{-}$is about 2.5 meter. So for $\mathrm{N}=26$ will get a better than $95 \%$ probability of a successful hypothesis test. Considering the upper and lower limit integers as rejected integers, we actually choose the value of $N+1$ in our hypothesis test.

How many steps it take for the normalized $\mathrm{P}\left(\mathrm{Z}_{\mathrm{k}}{ }^{*} \mid \mathrm{n}\right)$ to convene to 1 corresponds to how long it will take to determine the ambiguity integer. When the sample interval is ten second, $\mathrm{k}=30$ (steps), it will take about 5 minutes. And for $\mathrm{k}=120$, it will take about 20 minutes.

Once the ambiguity integer is determined, the routine Kalman filter is applied. Figure 19 and Figure 20 show the results. The dotted broken line is the true position. The broken line is the Kalman filter output. The solid line is the raw 
data calculated from $\mathrm{Z}_{\mathrm{k}}{ }^{*}$.

The application of MMEA in GPS differential phase measurement is simulated in the MATLAB software package on PC-486. The main reason to choose the MATLAB software package is its convenience of the matrix calculation. In the appendices, three MATLAB scripts are listed. These are very much self-explained programs. The Appendix A, which is the program generate the $Z_{k}$ measurement, has inputs of $x 0, w 0$, v0 and outputs of $Z$, and $x t$. The $x 0$ is the initial state, the w0 is the model driving noise amplitude and the v0 is the measurement noise amplitude. The output of $\mathrm{Z}$ is the simulated measurement and the $x t$ is the true state value(the GPS user position). The Appendix B, which is the program do the hypothesis tests, has inputs of $\mathrm{P} 0$, w0, v0, n, Z and an output of matrix fq. The $P 0$ is the initial noise variance, and the $\mathrm{n}$ is the integer value range of hypothesis tests. The matrix fq tells which hypothesis integer is correct. The Appendix C, which is a routine Kalman filter program, has inputs of $\mathrm{x} 0$, $\mathrm{P} 0$, w0, $\mathrm{v} 0, \mathrm{Z}$ and outputs of $\mathrm{X}$ which is the Kalman filter output. The Kalman filter algorithm and the Multiple Model Estimation Algorithm are used in the simulations. 


\section{CHAPTER VIII}

\section{SUMMARY}

\section{REVIEW}

The application of MMEA to the measurement of phase difference of GPS signal carrier is positively tested in the simulation. It has yet to be tested in the actual GPS system. It also has to be compared with other precise surveying methods, such as precise surveying by using $P$ code. Such a test must be done by an authorized users of the $P$ code.

\section{FUTURE WORK}

To use MMEA method in determining the initial ambiguity integer provides a practical option in precision survey. But there is still one more practical problem that should be solved in future work. The MMEA requires continuous tracking of the satellite signal phase after the initial measurements as mentioned in Chapter VI. Continuous tracking of the satellite signal phase sometimes is difficult in the dynamic situation. Once the tracking of the phase difference is interrupted, the surveying process has to use the MMEA to determine the initial 
ambiguity integer again. The process of determining the initial ambiguity integer may take about 20 minutes or longer. This is very time consuming and inefficient.This limitation will refrain the MMEA's solution from many applications. In order to solve this problem, the Discrete Markov Model[7] and Verterbi Algorithm[8] are introduced. The basic concept is that we measure the phase difference between the point $B$ and the point $C$ (as shown in Figure 11) without the assumption that the full wavelength of $\mathrm{Z}_{\mathrm{k}}$ has to be known after $\mathrm{K}=$ 0. This means there will be no requirement to continuously to track the satellite carrier phase difference. All the phase difference measurements $Z_{k}{ }^{*}=Z_{k}, \ldots, Z_{1}$, $\mathrm{Z}_{0}$ are measured between 0 to 1 wavelength plus their respective unknown integers $N^{*}=N_{k} \ldots N_{1}, N_{0}$. The Discrete Markov Model can be used to characterize the change of $\mathrm{N}^{*}$. And the Verterbi Algorithm can be used to find out the right transition sequence of $\mathrm{N}^{*}$. This proposal will result in a very flexible and efficient surveying method. This method, however, will be a post-experiment processing with no potential of being real time. 


\section{REFERENCES}

1. The Institute of Navigation, Global Positioning System, Volume I, II, III, 1984.

2. D.T. Magill, "Optimal Adaptive Estimation of Sampled Stochastic Processes", IEEE Trans. on Automatic Control, Vol AC-10, No. 4, pp. 434439, Oct. 1965.

3. Mohinder S. Grewal, Angus P. Andrews, Kalman Filtering, Theory and Practice, Prentice Hall, Inc., Englewood Cliffs, New Jersey, 1993.

4. J.J. Spilker, Jr., "Global Positioning System: Signal Structure and Performance Characteristics," AGARD-AG-245, July 1979.

5. Marthe Friis, O.S. Friis, GPS Satellite Navigation, Rauff \& Soerensen Ltd, DK-9530 Stoevring, Denmark, 1987.

6. Robert Grover Brown, Patrick Y.C. Hwang, Introduction to Random Signals and Applied Kalman Filtering, Second Edition, John Wiley \& Sons, Inc., New York, 1992.

7. Lawrence R. Rabiner, "A Tutorial on Hidden Markov Models and Selected Applications in Speech Recognition," Proc. of The IEEE, Vol 77, No. 2, pp. 257-286, February 1989.

8. Sophocles J. Orfanidis, Optimum Signal Processing, An Introduction, Second Edition, Macmillan Publishing Company, New York, 1988. 
APPENDIX A

THE GENERATION OF $\mathrm{Z}_{k}$ MEASUREMENT 


\section{APPENDIX A}

\section{THE GENERATION OF $Z_{\mathrm{k}}$ MEASUREMENT}

function $\mathrm{mz}=\mathrm{fkgz}(\mathrm{x} 0, \mathrm{w} 0, \mathrm{v} 0)$

$\% \quad$ The kalman Filter Simulation Program

$\% \quad$ The Generation of $\mathrm{Zk}$ sequence.

$\% \quad \mathrm{Zk}=\mathrm{Hk} \cdot \mathrm{Xk}+\mathrm{Vk}$

$\% \quad \mathrm{Xk}+1=\mathrm{Fk} . \mathrm{Xk}+\mathrm{Wk}$

$\% \quad \mathrm{Fk}=1$;

$\% \quad \mathrm{Hk}=\cos \mathrm{B} / \mathrm{L} ; \mathrm{L}$ is the wavelength, $\mathrm{B}$ is angle to the satellite

$k=1: 500$

$\mathrm{B}(\mathrm{k})=\mathrm{pi} / 3-\left(\mathrm{pi} /\left(360^{*} 6\right)\right)^{*}(\mathrm{k}-1)$;

$\mathrm{H}(\mathrm{k})=\cos (\mathrm{B}(\mathrm{k})) / 19$;

rand('normal')

$\mathrm{v}(\mathrm{k})=(\mathrm{v} 0)^{*} \mathrm{rand}(1,500)$;

$\mathrm{w}(\mathrm{k})=(\mathrm{w} 0)^{*} \mathrm{rand}(1,500)$;

$\mathrm{xt}(1)=\mathrm{x} 0$;

for $k=1: 499$;

$\mathrm{xt}(\mathrm{k}+1)=\mathrm{xt}(\mathrm{k})+\mathrm{w}(\mathrm{k})$;

end

for $k=1: 500$;

$\mathrm{z}(\mathrm{k})=\mathrm{xt}(\mathrm{k}) * \mathrm{H}(\mathrm{k})+\mathrm{v}(\mathrm{k})$;

end

$\mathrm{mz}=[\mathrm{Z} 1 ; \mathrm{xt}]$; 
APPENDIX B

THE AMBIGUITY INTEGER HYPOTHESIS TESTS 
APPENDIX B

\section{THE AMBIGUITY INTEGER HYPOTHESIS TESTS}

function $p p=f m x(P 0, w 0, v 0, n, Z)$

\% The kalman Filter Simulation Program

\% Using the MMEA model to calculate the prevailing hypothesis.

$\%$ The output of the program is the $\mathrm{P}\left(\mathrm{Zk}^{*} / \mathrm{N}\right), \mathrm{N}$ is the different hypothesis.

$\%$ The $\mathrm{x} 0$ is the initial estimate, $\mathrm{P} 0$ the initial covariance, w0,v0 $\sim \mathrm{Qk}, \mathrm{Rk}$

$\% \quad$ the $\mathrm{n}$ is the range of hypothesis, $\mathrm{Z}$ the measurement input.

$\% \quad \mathrm{Zk}=\mathrm{Hk} \cdot \mathrm{Xk}+\mathrm{Vk}$

$\% \quad \mathrm{Xk}+1=\mathrm{Fk} \cdot \mathrm{Xk}+\mathrm{Wk}$

$\% \quad$ with

$\% \quad \mathrm{Rk}=(\mathrm{v} 0)^{\wedge} 2$

$\% \quad \mathrm{Qk}=(\mathrm{w} 0)^{\wedge} 2$

$\% \quad \mathrm{Fk}=1$

$\% \quad \mathrm{P}(1,1)=\mathrm{P} 0$

$\% \quad \mathrm{Hk}=\cos \mathrm{B} / \mathrm{L} ; \mathrm{L}$ is the wavelength, $\mathrm{B}$ is angle to the satellite

$\mathrm{k}=1: 500$

$\mathrm{B}(\mathrm{k})=\mathrm{pi} / 3-\left(\mathrm{pi} /\left(360^{*} 6\right)\right)^{*}(\mathrm{k}-1)$;

$\mathrm{H}(\mathrm{k})=\cos (\mathrm{B}(\mathrm{k})) / 19$;

$\mathrm{Rk}=(\mathrm{v} 0)^{\wedge} 2$

$\mathrm{Qk}=(\mathrm{w} 0)^{\wedge} 2$;

$\mathrm{P}(1)=\mathrm{P} 0$;

$\mathrm{Zl}=\mathrm{Z}$-fix $(\mathrm{Z}(1))$;

$\mathrm{Zn}=\mathrm{Zl}$;

for $i=1: n$; 
$\mathrm{Zn}=[\mathrm{Zl}-\mathrm{i} ; \mathrm{Zn} ; \mathrm{Zl}+\mathrm{i}]$

end

$\mathrm{fc}=\operatorname{ones}\left(1,2^{*} \mathrm{n}+1\right)$

$\mathrm{x} 0=0$

$\mathrm{X} 1=\mathrm{x} 0^{*}$ ones $\left(1,2^{*} \mathrm{n}+1\right)$;

for $k=1: 500$, $\mathrm{G}=\mathrm{P}(\mathrm{k})^{*} \mathrm{H}(\mathrm{k}) /\left(\mathrm{H}(\mathrm{k})^{*} \mathrm{P}(\mathrm{k})^{*} \mathrm{H}(\mathrm{k})+\mathrm{Rk}\right) ;$

for $m=1: 2^{*} n+1$,

$\mathrm{fk}(\mathrm{m})=\left(1 / \mathrm{sqrt}\left(2^{*} \mathrm{pi}^{*}\left(\mathrm{H}(\mathrm{k})^{*} \mathrm{P}(\mathrm{k})^{*} \mathrm{H}(\mathrm{k})+\mathrm{Rk}\right)\right)\right)^{*} \exp (-(\mathrm{Zn}(\mathrm{m}, \mathrm{k})-\mathrm{H}(\mathrm{k})$

*X1(m))^2/(2*(H(k)*P(k)*H(k)+Rk)));

$\mathrm{X} 2(\mathrm{~m})=\mathrm{X} 1(\mathrm{~m})+\mathrm{G}^{*}\left(\mathrm{Zn}(\mathrm{m}, \mathrm{k})-\mathrm{H}(\mathrm{k})^{*} \mathrm{X} 1(\mathrm{~m})\right) ;$

$\mathrm{X} 1(\mathrm{~m})=\mathrm{X} 2(\mathrm{~m})$;

$\mathrm{fc}(\mathrm{m})=\mathrm{fc}(\mathrm{m})^{*} \mathrm{fk}(\mathrm{m})$

end

$\mathrm{P}(\mathrm{k}+1)=\left(1-\mathrm{G}^{*} \mathrm{H}(\mathrm{k})\right)^{*} \mathrm{P}(\mathrm{k})$;

$\mathrm{fc}=\mathrm{fc} / \mathrm{sum}(\mathrm{fc})$;

if $\mathrm{k}==1$

$\mathrm{fq}=\mathrm{fc}$;

else

$\mathrm{fq}=\left[\mathrm{fq} \mathrm{fc}^{\prime}\right]$

end

$\%$ The fq will be $\mathrm{m}$ by $\mathrm{k}$ matrix. $\mathrm{m}$ is number of hypo, $\mathrm{k}$ is time series.

end

$\mathrm{pp}=\mathrm{fq}$; 
APPENDIX C

KALMAN FILTERING OF $\mathbf{Z}_{k}$ 


\section{APPENDIX C}

\section{KALMAN FILTERING OF $\mathrm{Z}_{\mathrm{k}}$}

function $\mathrm{xx}=\mathrm{fkx}(\mathrm{x} 0, \mathrm{P} 0, \mathrm{w} 0, \mathrm{v} 0, \mathrm{Z})$

\% The kalman Filter Simulation Program

$\% \quad$ The best estimation of $\mathrm{X}$ and prior $\mathrm{X}$ -

$\% \quad \mathrm{Zk}=\mathrm{Hk} \cdot \mathrm{Xk}+\mathrm{Vk}$

$\% \quad \mathrm{Xk}+1=\mathrm{Fk} \cdot \mathrm{Xk}+\mathrm{Wk}$

$\% \quad$ with

$\% \quad \mathrm{Rk}=(\mathrm{v} 0)^{\wedge} 2$

$\% \quad \mathrm{Qk}=(\mathrm{w} 0)^{\wedge} 2$

$\% \quad \mathrm{P} 1-=\mathrm{P}(1,1)$

$\% \quad \mathrm{Fk}=1$

$\% \quad \mathrm{Hk}=\cos \mathrm{B} / \mathrm{L} ; \mathrm{L}$ is the wavelength, $\mathrm{B}$ is angle to the satellite

$\mathrm{k}=1: 500$;

$\mathrm{B}(\mathrm{k})=\mathrm{pi} / 3-\left(\mathrm{pi} /\left(360^{*} 6\right)\right)^{*}(\mathrm{k}-1)$;

$\mathrm{H}(\mathrm{k})=\cos (\mathrm{B}(\mathrm{k})) / 19$;

$\mathrm{Rk}=(\mathrm{v} 0)^{\wedge} 2$

$\mathrm{Qk}=(\mathrm{w} 0)^{\wedge} 2$;

$\mathrm{P}(1,1)=\mathrm{P} 0$;

$\mathrm{X}(1,1)=\mathrm{x} 0$;

for $k=1: 500$

$\mathrm{G}(\mathrm{k})=\mathrm{P}(1, \mathrm{k}) * \mathrm{H}(\mathrm{k}) /\left(\mathrm{H}(\mathrm{k}) * \mathrm{P}(1, \mathrm{k})^{*} \mathrm{H}(\mathrm{k})+\mathrm{Rk}\right) ;$

$\mathrm{X}(2, \mathrm{k})=\mathrm{X}(1, \mathrm{k})+\mathrm{G}(\mathrm{k})^{*}\left(\mathrm{Z}(\mathrm{k})-\mathrm{H}(\mathrm{k})^{*} \mathrm{X}(1, \mathrm{k})\right)$;

$\mathrm{P}(2, \mathrm{k})=\left(1-\mathrm{G}(\mathrm{k})^{*} \mathrm{H}(\mathrm{k})\right)^{*} \mathrm{P}(1, \mathrm{k})$;

$\mathrm{X}(1, \mathrm{k}+1)=\mathrm{X}(2, \mathrm{k})$;

$\mathrm{P}(1, \mathrm{k}+1)=\mathrm{P}(2, \mathrm{k})+\mathrm{Qk}$;

end

$\mathrm{xx}=\mathrm{X}$ 